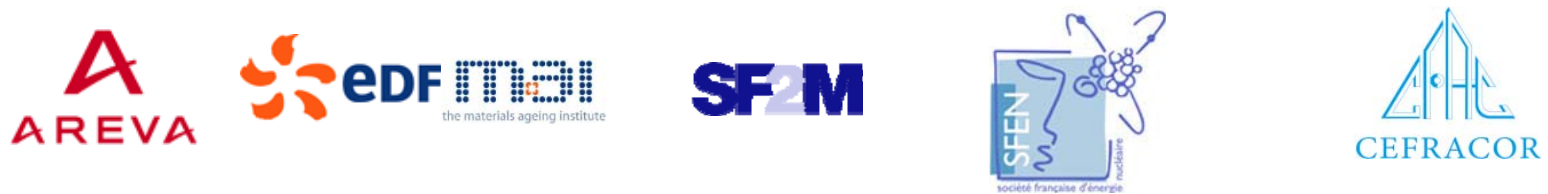

\section{MIN口S}

Centre of Excellence for Nuclear Materials

\section{Workshop}

Materials Innovation for Nuclear Optimized Systems

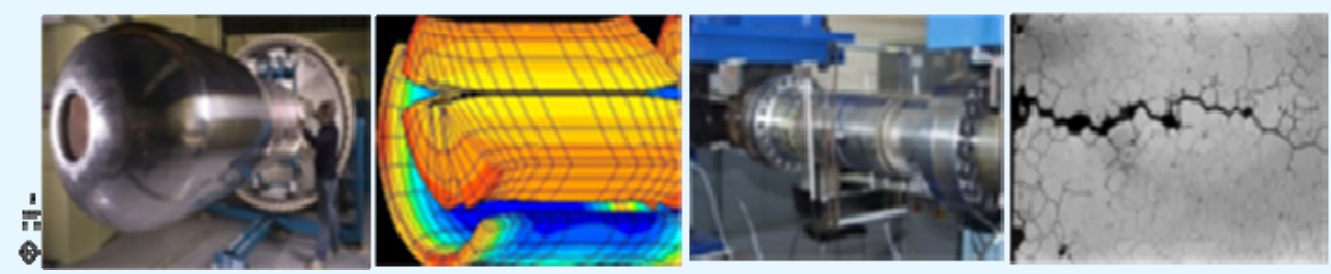

December 5-7, 2012, CEA - INSTN Saclay, France

\section{Benoît TANGUY et al. \\ CEA (France)}

The Irradiation-Assisted Stress Corrosion Cracking (IASCC) issue: some Examples of Studies Carried out at CEA

Workshop organized by:

Christophe GALLÉ, CEA/MINOS, Saclay - christophe.galle@cea.fr Constantin MEIS, CEA/INSTN, Saclay - constantin.meis@cea.fr 


\title{
The Irradiation-Assisted Stress Corrosion Cracking (IASCC) Issue: some Examples of Studies Carried out at CEA
}

\author{
Benoît TANGUY ${ }^{1}$, Maxime SAUZAY ${ }^{2}$, Christian ROBERTSON ${ }^{2}$, Stéphane PERRIN ${ }^{3}$ \\ ${ }^{1}$ CEA-DEN-DMN, Service d'Etudes des Matériaux Irradiés, SEMI (Saclay, France) \\ ${ }^{2}$ CEA-DEN-DMN, Service de Recherches Métallurgiques Appliquées, SRMA (Saclay, France) \\ ${ }^{3}$ CEA-DEN-DPC, Service de la Corrosion et du Comportement des Matériaux dans leur Environnement, SCCME (Saclay, France)
}

Irradiation assisted stress corrosion cracking (IASCC) is a problem of growing importance in pressurized water reactors (PWR). An understanding of the mechanism(s) of IASCC is required in order to provide guidance for the development of mitigation strategies. One of the principal reasons why the IASCC mechanism(s) has been so difficult to understand is the inseparability of the different IASCC potential contributors (radiation induced segregation (RIS) at grain boundaries, radiation induced microstructure (dislocations loops, voids, bubbles, phases), localized deformation under loading, irradiation creep and transmutations) evolutions due to neutron irradiation. While the development of some of the contributors (RIS, microstructure) with increasing doses are at least qualitatively well understood, the role of these changes on IASCC remains unclear. Fundamental studies related to the IASCC mechanisms can be divided on two main parts: (i) How the irradiation modifies the austenitic stainless steels (ASS) microstructure (and so the ASS mechanical behavior) as a function of dose, temperature, stress, spectrum and flux and how it affects the resistance of the ASS to SCC sensitivity and (ii) How the irradiation flux modifies the corrosion process themselves (oxidation) and how it may affect the SCC kinetics. For this last topic, both a modification of water chemistry (radiolysis) and a change of oxide are probably involved.

To answer these questions, parallel to experimental characterizations at different scales, development of modeling is of growing importance in the understanding of the basic mechanisms of IASCC but also of their interactions. This lecture describes some studies carried out at CEA in order to provide further understanding in the IASCC damage modeling. First part of this lecture describes the methodology carried out at CEA in order to provide more experimental data from constant load tests dedicated to the study of initiation of SCC on neutron irradiated stainless steel. A description of the autoclave recirculation loop [1] dedicated to SCC tests on neutron irradiated materials is then given. The main steps of the interrupted SCC tests carried are described relative to their objectives.

Second part of the lecture gives some insights of the effect of irradiation on the oxidation processes. Oxidation of stainless steel in PWR primary water at $325^{\circ} \mathrm{C}$ has been studied by investigating the influence of defects created at the alloy subsurface by proton irradiation performed before corrosion test. Corrosion experiments were performed during two different corrosion sequences using $\mathrm{H}_{2}{ }^{18} \mathrm{O}$ for the second corrosion one. The oxide layer was studied by SEM and TEM and could be divided in two parts: an external discontinuous layer composed of crystallites rich in iron and an internal continuous one richer in chromium. Tracer experiments underlined that the growth of this protective scale was due to oxygen diffusion in the grain boundary of the oxide layer. Defects created by irradiation have an effect on the two oxide layers. They are preferential nucleation site for the external layer and so increase the density of the crystallites. They also induce a slower diffusion of oxygen in the internal layer.

The third part of the lecture focuses on the plasticity of the irradiated stainless steel at the grain scale. The goal of this work is to model irradiation-induced strain localization at the grain scale, using 3D dislocation dynamics (DD) simulations. More specifically, it is attempted to predict the number of shear bands affecting (deforming) the grain boundaries, in presence of a representative irradiation defect cluster populations. 
In practice 2 types of DD simulations were used, based on their complementary capacities and limitations. Simulations (Figure 1) where irradiation-induced defect clusters are treated as planar obstacles to dislocation motion were carried out. This description has reduced computational load and is compatible with the introduction of thermally activated cross-slip for simulating multiple slip band formation. Shear band spacing and plastic strain spreading obtained using these simulations show that spacing increases with increasing dose, grain size and increasing stacking fault energy (SFE). The proposed model has been successfully extrapolated to grain sizes and defect cluster populations representative of actual fcc alloys, submitted to typical PWR neutron irradiation conditions.

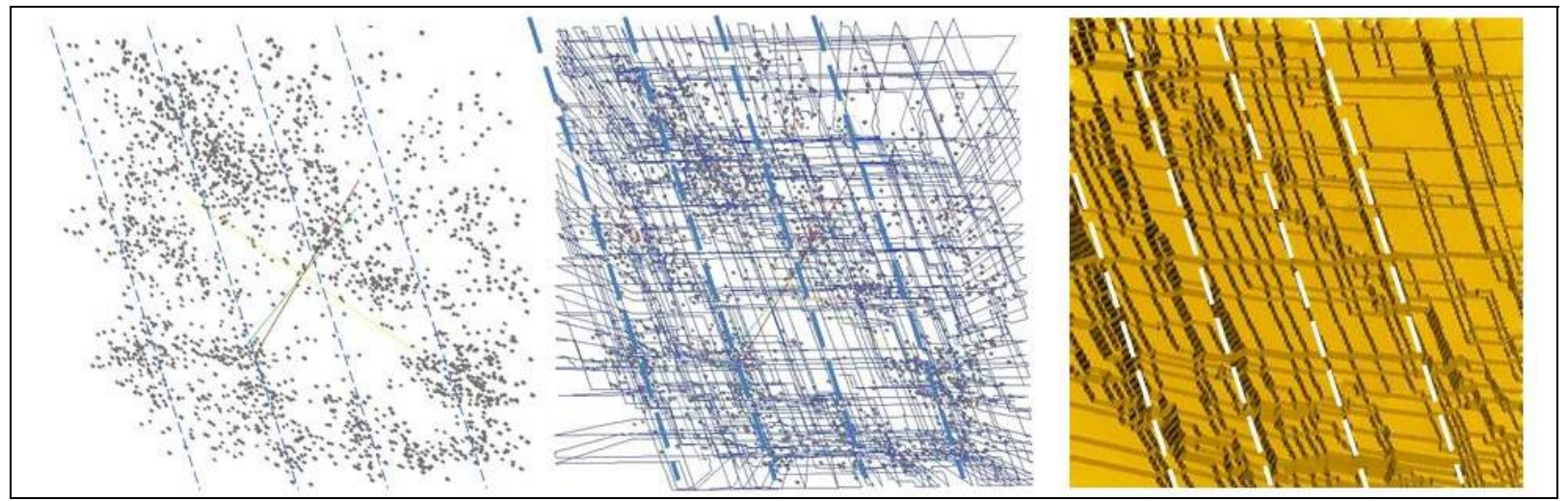

Fig. 1: Clear bands and strain localization predicted using Type-2 DD simulations. Left image: the represented loop-facets are those potentially absorbed by mobile screw dislocations. High density of absorbed loops materializes the channel position. Central image: swept loopfacets and corresponding dislocation structures. Right image: plastic strain mapping in grain boundary corresponding to left and central images.

Finally, simulation results to assess the influence of slip localization effect, which is an important feature of plasticity in irradiated ASS's, on the grain boundary stress-strain fields are presented. Slip localization is known to trigger grain boundary brittle fracture. For predicting the local stress fields, an elastoplastic slip band is assumed to be embedded at the surface of an elastic matrix. Numerous FEs computations have been carried out allowing the proposal of analytical formulae describing the grain boundary (GB) normal stress fields depending on clear band length and thickness, Schmid factor, slip band critical shear stress and remote stress mainly. Finally, finite fracture mechanics is applied, together with both critical GB fracture energy and stress criteria. This leads to analytical formulae as simple as the ones deduced from the pile-up theory, but taking into account the channel thickness.

\section{References}

[1] B. Tanguy, C. Pokor, A. Stern, P. Bossis, Initiation stress threshold Irradiation Assisted Stress Corrosion Cracking criterion assessment for core internals in PWR environment. ASME Pressure Vessels and Piping Division Conference, July 17-21, 2011, Baltimore (MD), USA.

\section{Acknowledgements}

The studies presented in this paper have been performed within the frame of collaborative works with EDF and/or with the European program (FP7) PERFORM-60. The CEA DEN-RSTB, projects RACOC and MASOL are also acknowledged for financial and scientific support. 
DE LA RECHERCHE À L'INDUSTRIE
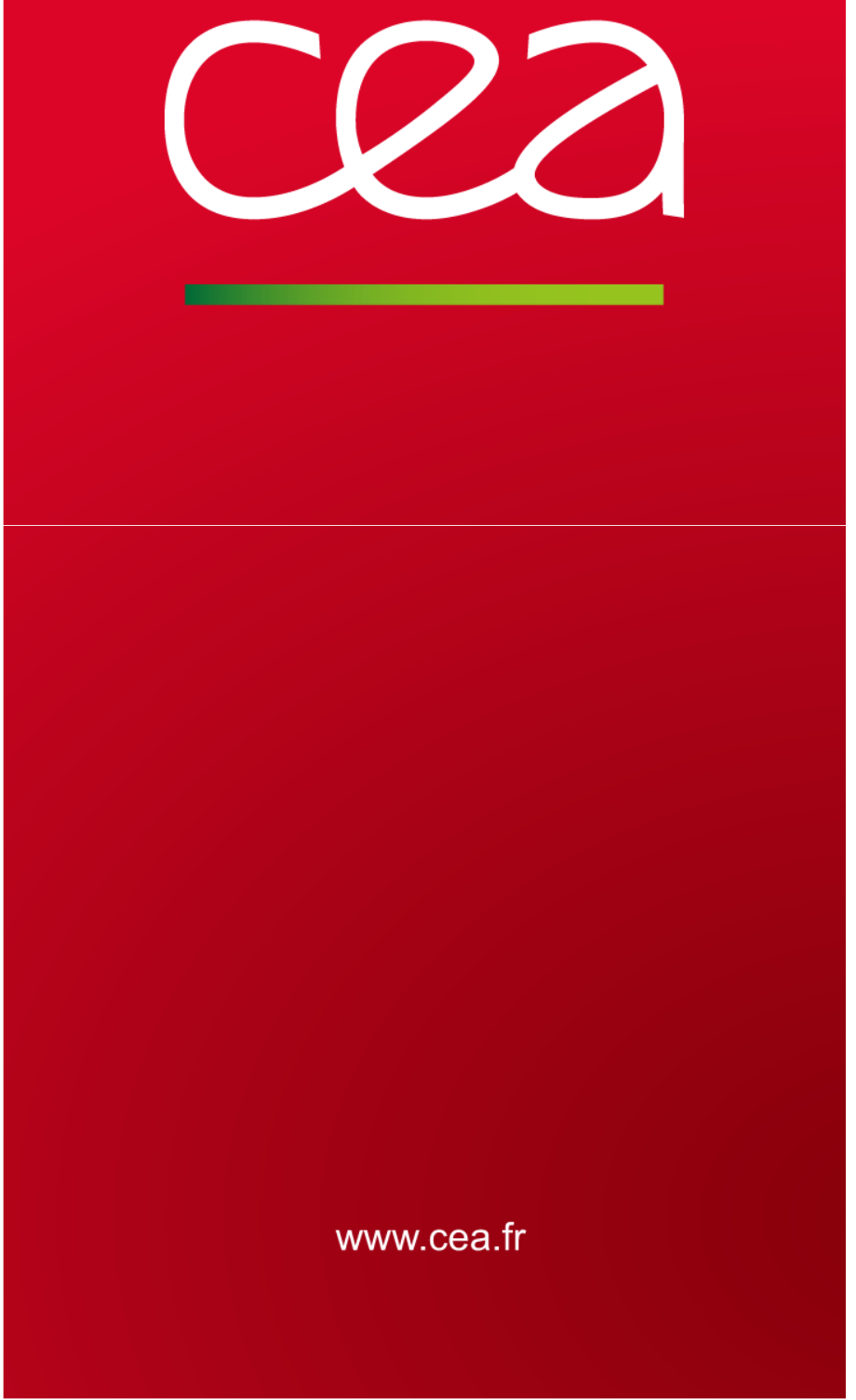

The Irradiation-Assisted Stress Corrosion Cracking (IASCC) issue: some examples of studies carried out at CEA

B. Tanguy ${ }^{1}$, M. Sauzay2 , C. Robertson'2, S. Perrin ${ }^{3}$

1: Section for Research on Irradiated Materials

2: Section for Research on Applied Metallurgy

3: Service de la Corrosion et du Comportement des Matériaux dans leur Environnement

DEN, CEA Saclay

MINOS Workshop, Materials Innovation for Nuclear Optimized Systems December 5-7, 2012, CEA - INSTN Saclay, France 


\section{Cea Background : Structural integrity of Core Internals}

$\because \mathrm{MINDS}$

Severe irradiation conditions in PWR core (RPV+internals)

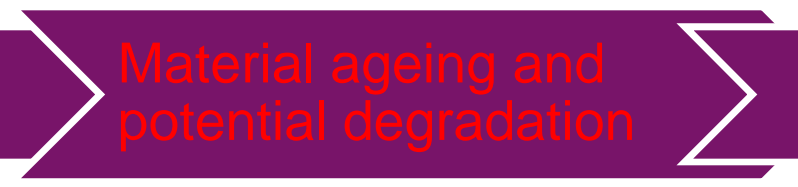

Limit of reactor operational life
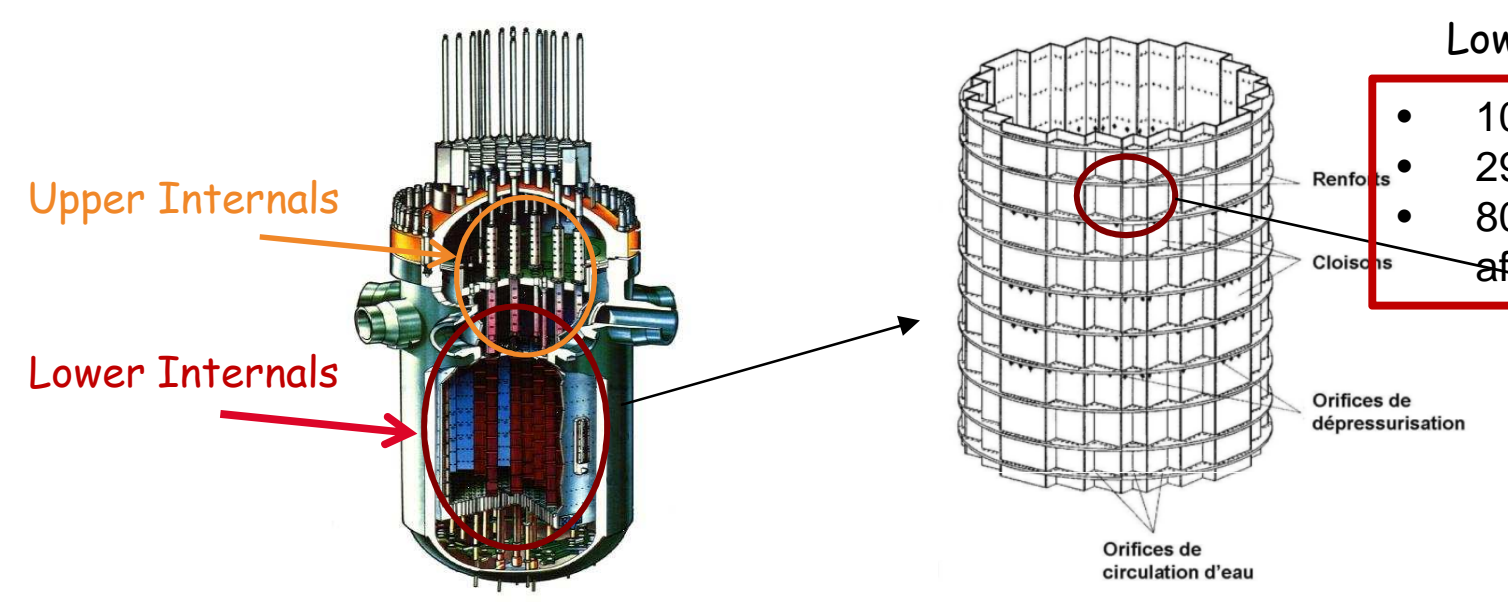

- Field of experience: IASCC of the baffle/former bolts

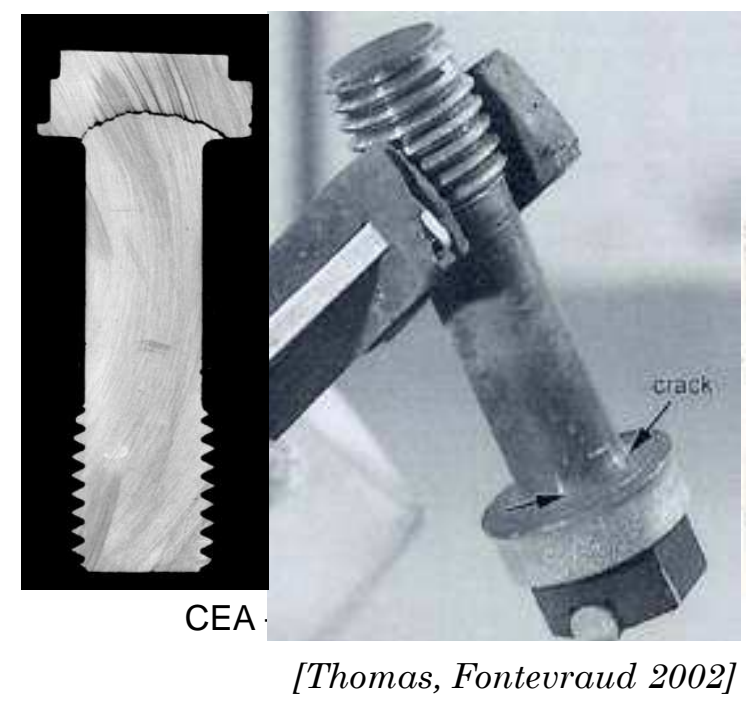

$\rightarrow I G$ Crack at the head to shank transition region

$\left(8.5 \mathrm{dpa}-300^{\circ} \mathrm{C}\right)$

\section{-> Focus on IASCC initiation for PWR's bolts}

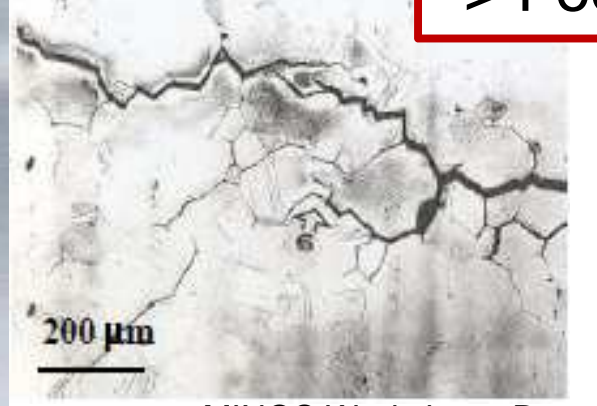

The internals lifetime has an important impact on the nuclear power plant lifetime because the cost and difficulty of their replacement 


\section{Cla IASCC Initiation: Mechanistic issues}

\section{MIN口S}

Simultaneous effects of radiation, stress and high temperature water environment

\section{Irradiation}

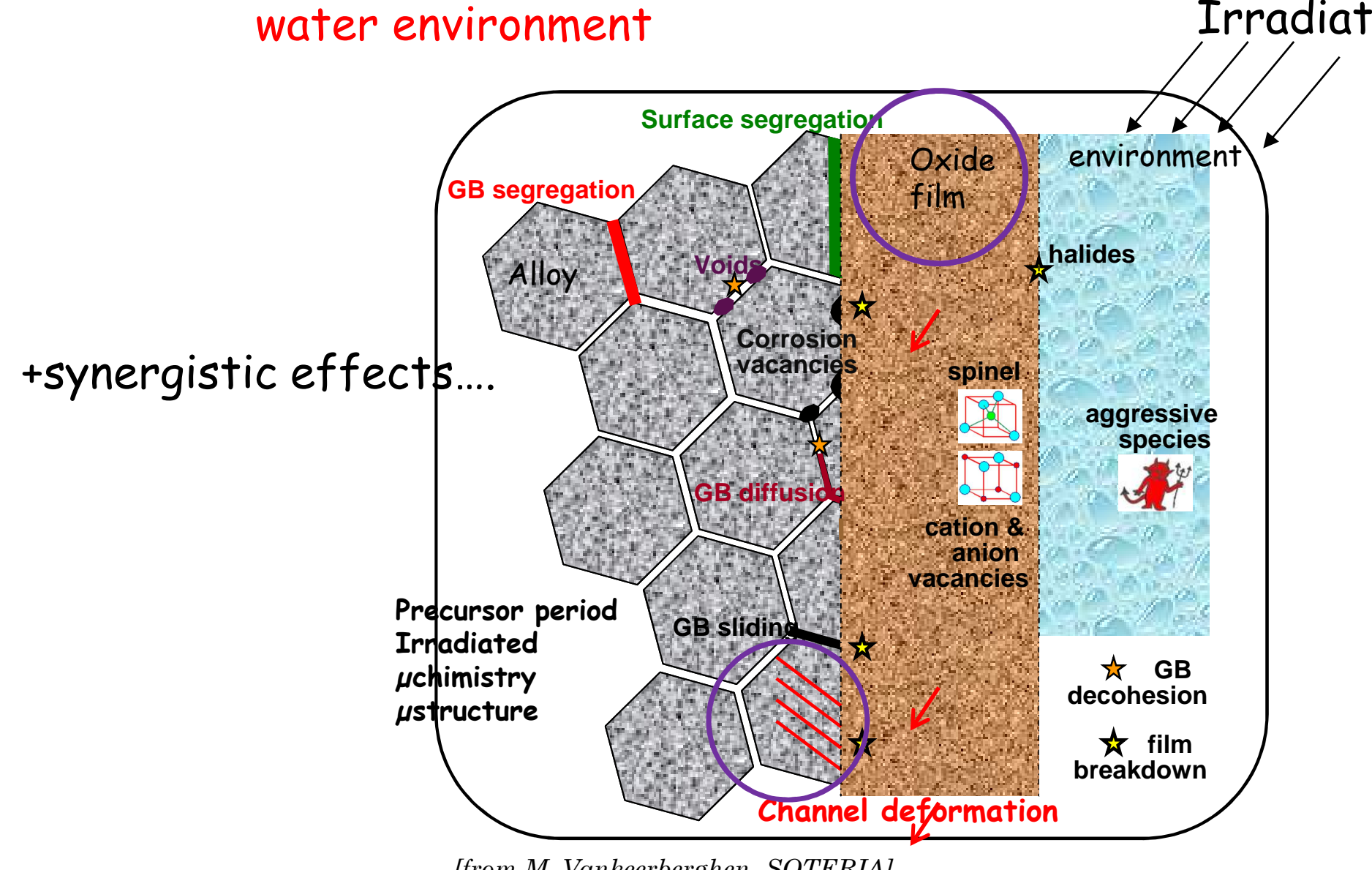

[from M. Vankeerberghen, SOTERIA]

$\rightarrow$ mechanisms understanding of IASCC initiation and its modelling are still under investigation 


\section{CEA CONTENT}

\section{MINDS}

- Background

- Initiation Stress Threshold IASCC Criterion Assessment

- Influence of irradiation on the oxide layer growth mechanism and on diffusion process in the oxide layer

- Effect of localization on Grain boundary microcracks nucleation

- Investigation of clear bands formation mechanisms 


\section{INITIATION STRESS}

THRESHOLD IASCC CRITERION ASSESSMENT 


\section{Cea Objectives and methodology}

MINDS Motivation: Industrial interest to establish an IASCC fracture criteria to understand and predict life duration of the bolt assembly. Sensitivity to first order parameters (Temperature, stress, deformation mode, irradiation, chemical composition)

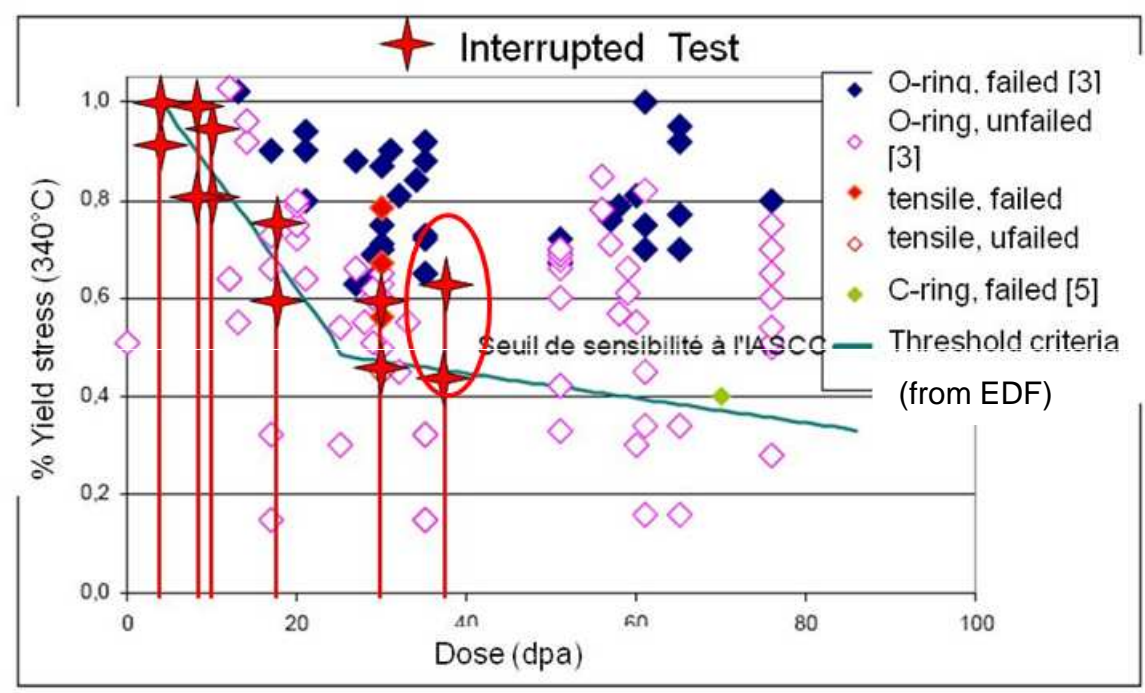

-Environment: Simulated PWR: 1200 ppm B, 2 ppm Li, $25<\mathrm{H} 2<35(\mathrm{cc} / \mathrm{kg})$

- $T($ test $)=340^{\circ} \mathrm{C}$

- Interrupted test $(1000 \mathrm{~h}+1000 \mathrm{~h})$ with two loading levels

- Loadings : constant load ( $\alpha_{i}$ irradiated yield stress at considered dose)

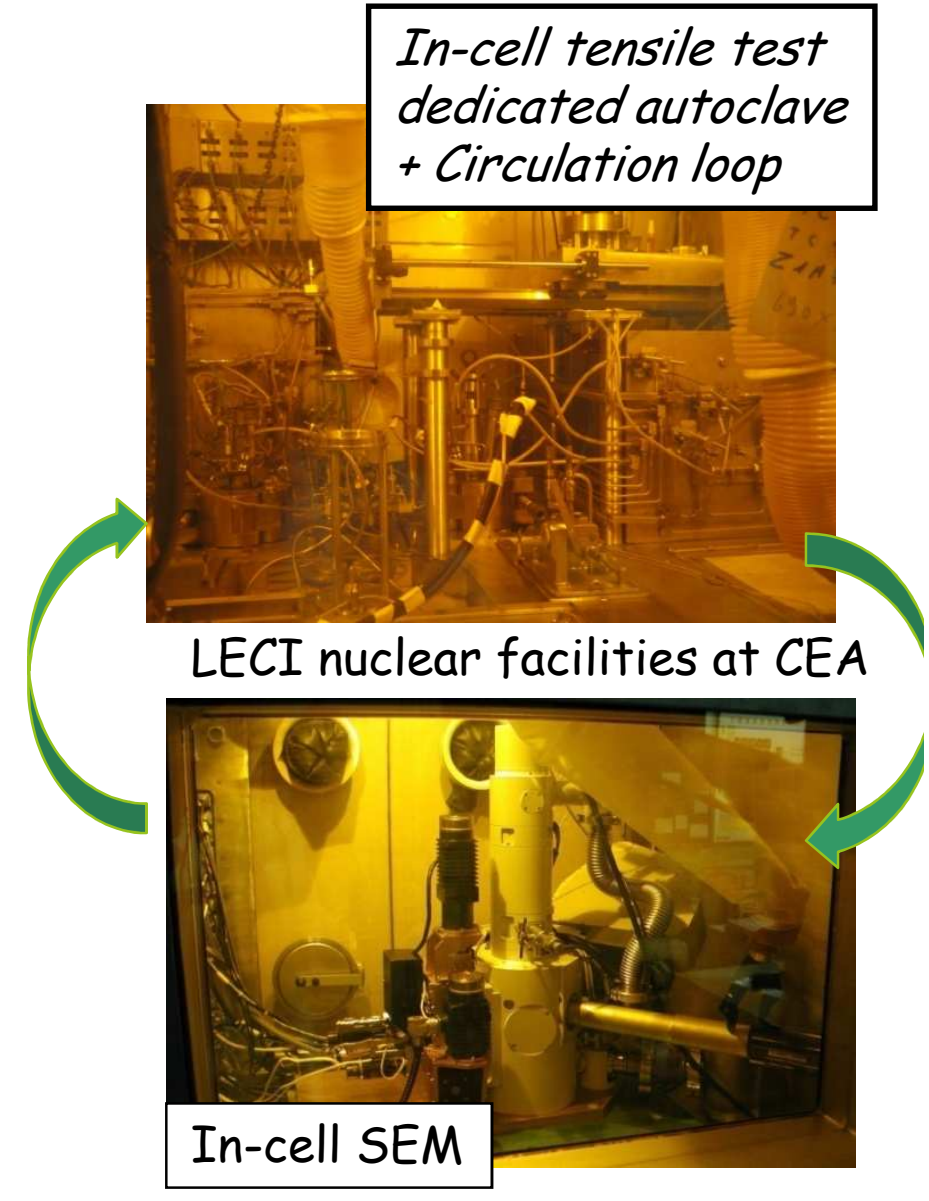




\section{Cea Methodology \& results examples}

\section{$\because \mathrm{MINDS}$}

Surface characterization: surface oxidation features of irradiated stainless steels in primary PWR environment + microcracks distribution

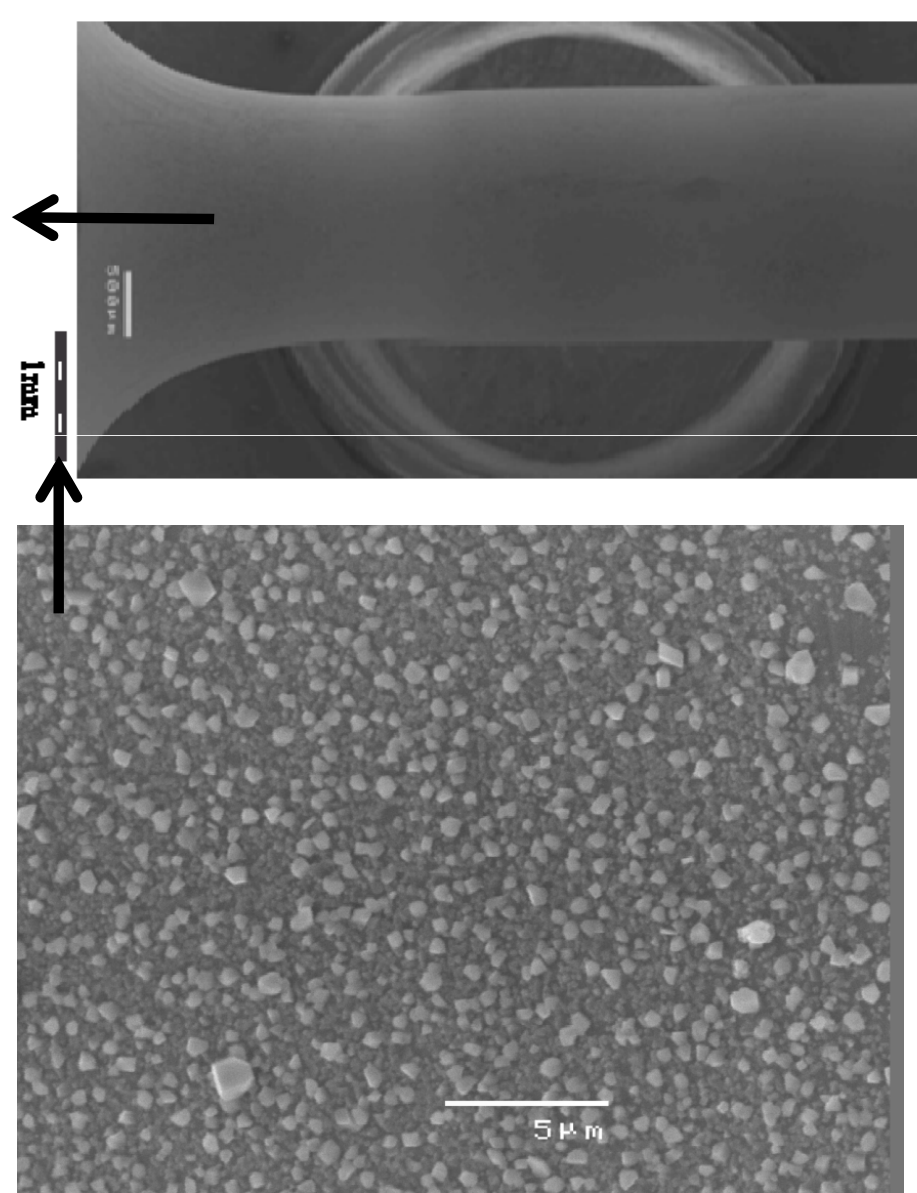

CEA - DEN

B. Tanguy

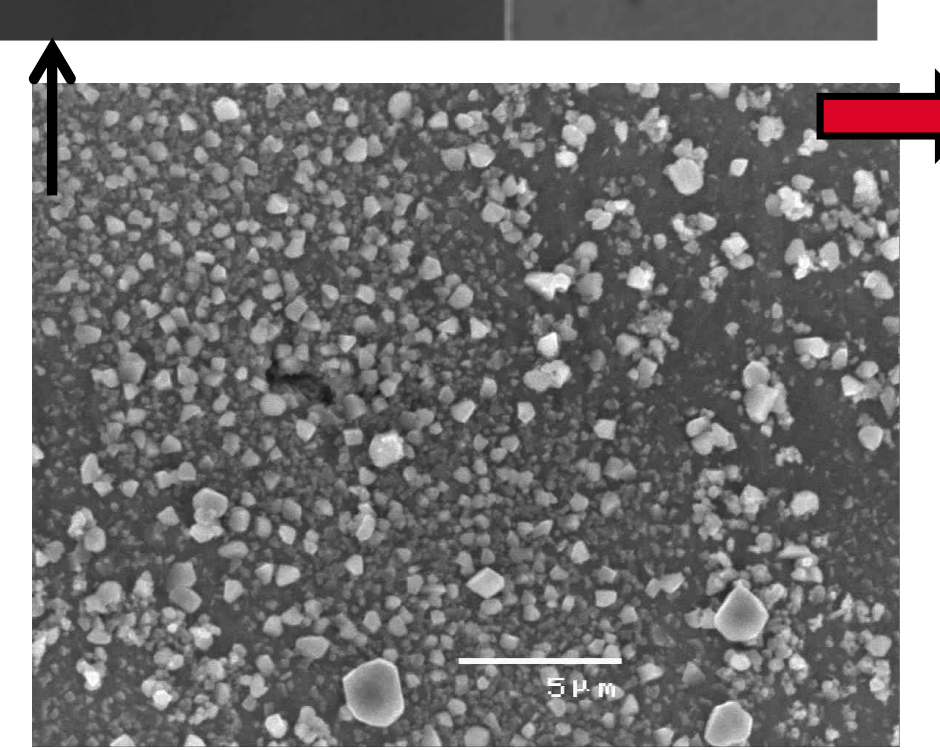

->On-going program
Microcracks size distribution as a function of dose and applied stress

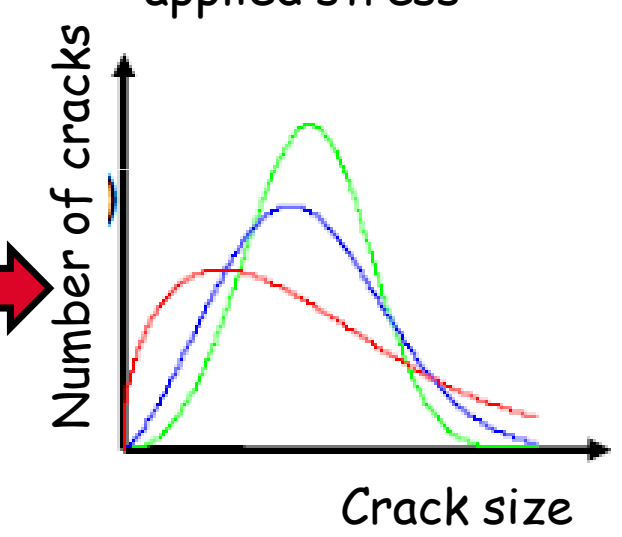

MINOS Workshop - December 5-7, 2012, CEA - INSTN Saclay, France 


\section{INFLUENCE OF IRRADIATION ON THE OXIDE LAYER GROWTH MECHANISM}

Service de la Corrosion et du Comportement des Matériaux dans leur Environnement 


\section{Cea Materials and methodology}

\section{MINDS}

-CW316L, 3MeV proton-irradiated ( 40 4 m depth, surface $\left.{ }^{i r r} \Phi \sim 1 \mathrm{~cm}\right), 2.10^{12}$ protons $/ \mathrm{cm}^{2} / \mathrm{s}$

- Sample preparation : SiC paper $(\rightarrow 4000)+$ diamond + OPS

- Methodology $\rightarrow$ Tracer experiments :

-1st corrosion sequence with $\mathrm{H}_{2}{ }^{16} \mathrm{O}$ media

- $2^{\text {nd }}$ corrosion sequence with $\mathrm{H}_{2}{ }^{16} \mathrm{O} / \mathrm{H}_{2}{ }^{18} \mathrm{O}$

- Localisation of ${ }^{18} \mathrm{O}$ and ${ }^{16} \mathrm{O}$ in the oxide layer

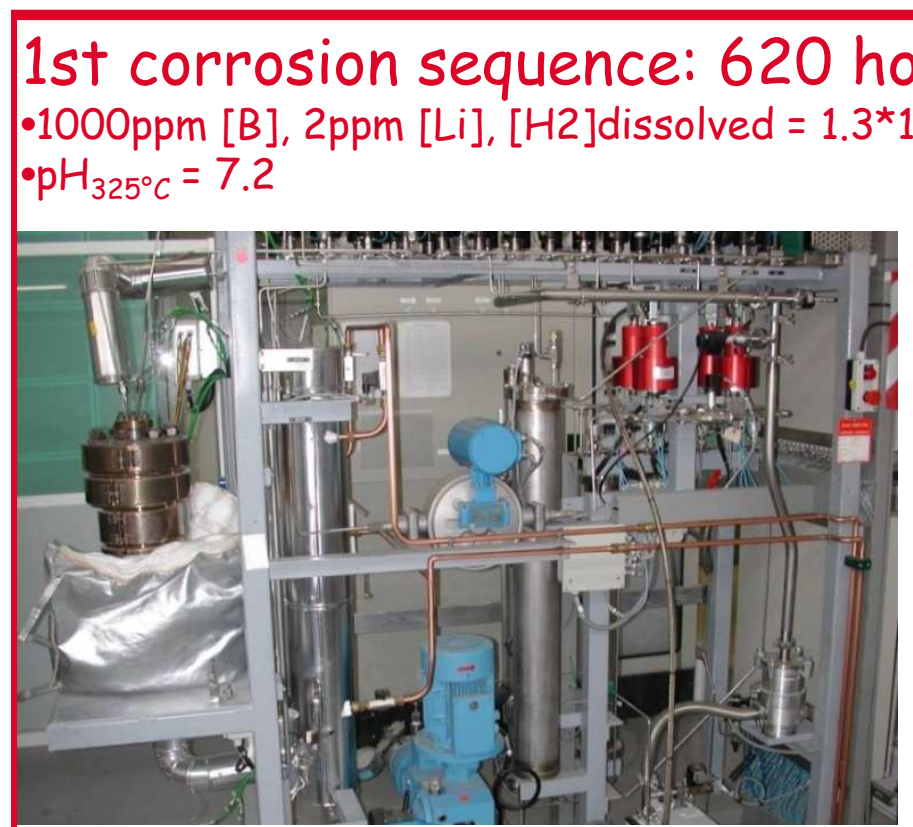

Corrosion loon at LECA. T $=325^{\circ} \mathrm{C} . \mathrm{P}=155 \mathrm{bar}$

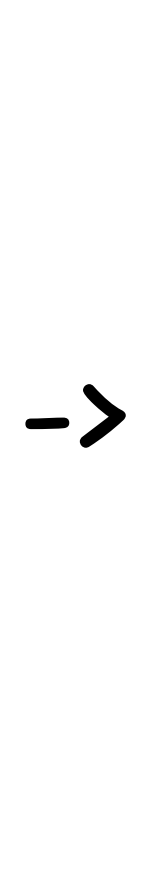

IMINOS Workshop - 2nd corrosion sequence:

$\cdot 1000 \mathrm{ppm}[\mathrm{B}], 2 \mathrm{ppm}[\mathrm{Li}],[\mathrm{H} 2]$ dissolved $=1.3^{* 10^{-3}} \mathrm{~mol}^{-\mathrm{I}^{-1}}$ $\cdot \mathrm{pH}_{325^{\circ} \mathrm{C}}=7.2$

$>17 \mathrm{~h}$ : determination of diffusion coefficient

$>$ 404h: determination of corrosion mechanism

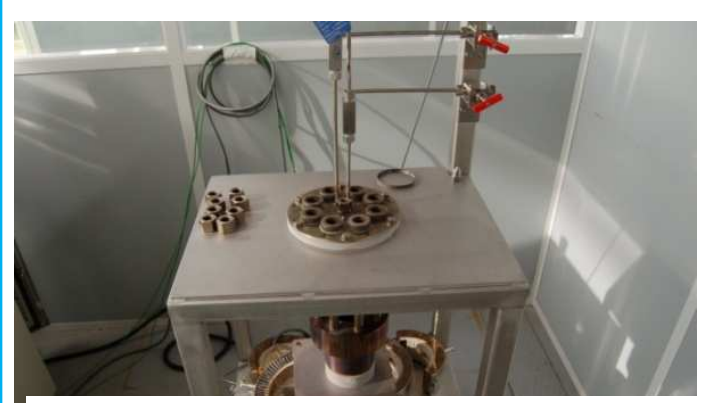

Titanium autoclave $(300 \mathrm{ml}), T=325^{\circ} \mathrm{C}, \mathrm{P}=128 \mathrm{bar}$ 


\section{cea}

\section{Effect of irradiation on the external layer (after 1st sequence)}

$\because$ MINDS TEM Characterization after 1024 hours (coop. with M.Sennour and C. Duhamel (ENSMP))

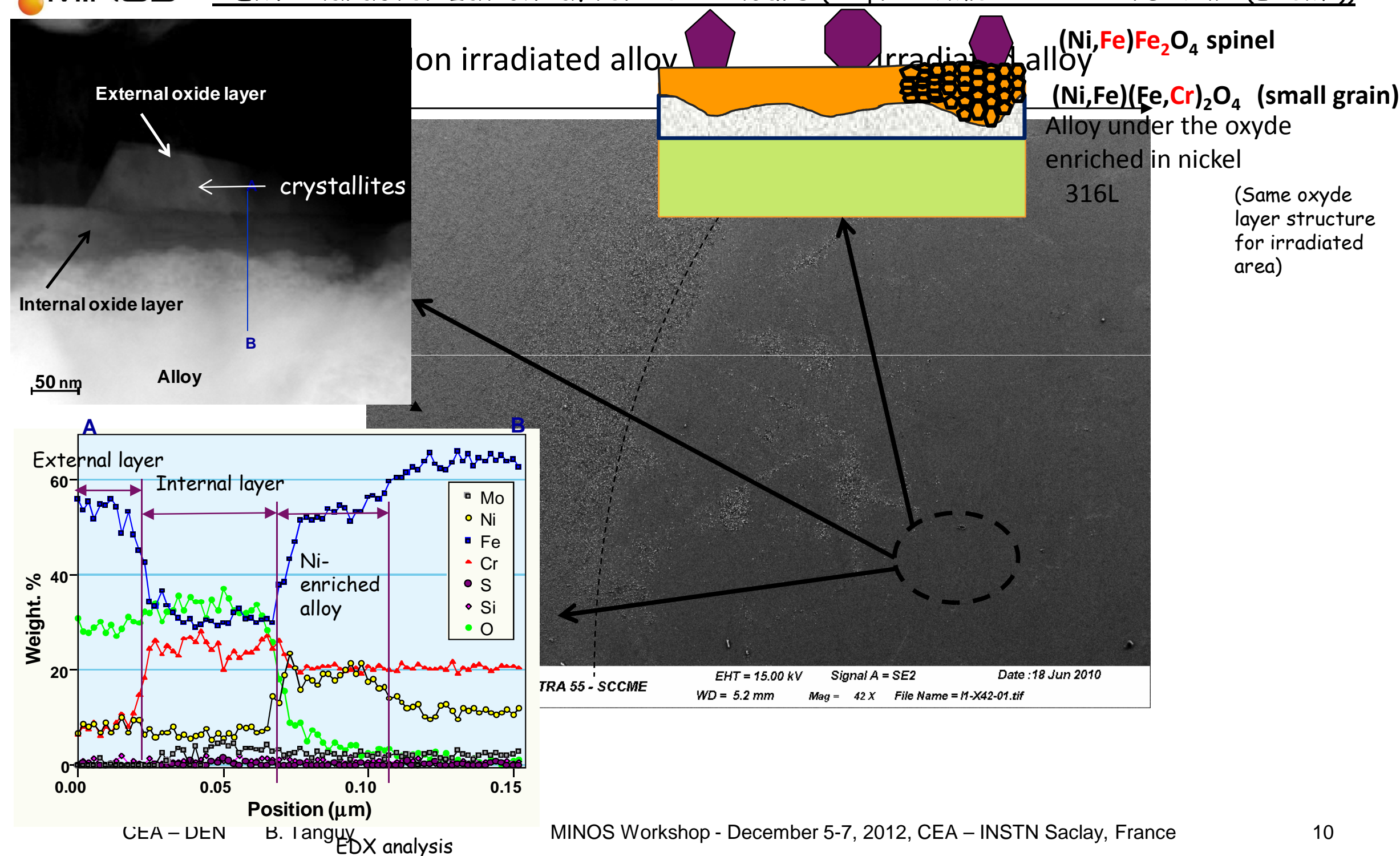




\section{cea}

Effect of irradiation on the external layer (after 1st sequence)

MIN口S

Non irradiated alloy
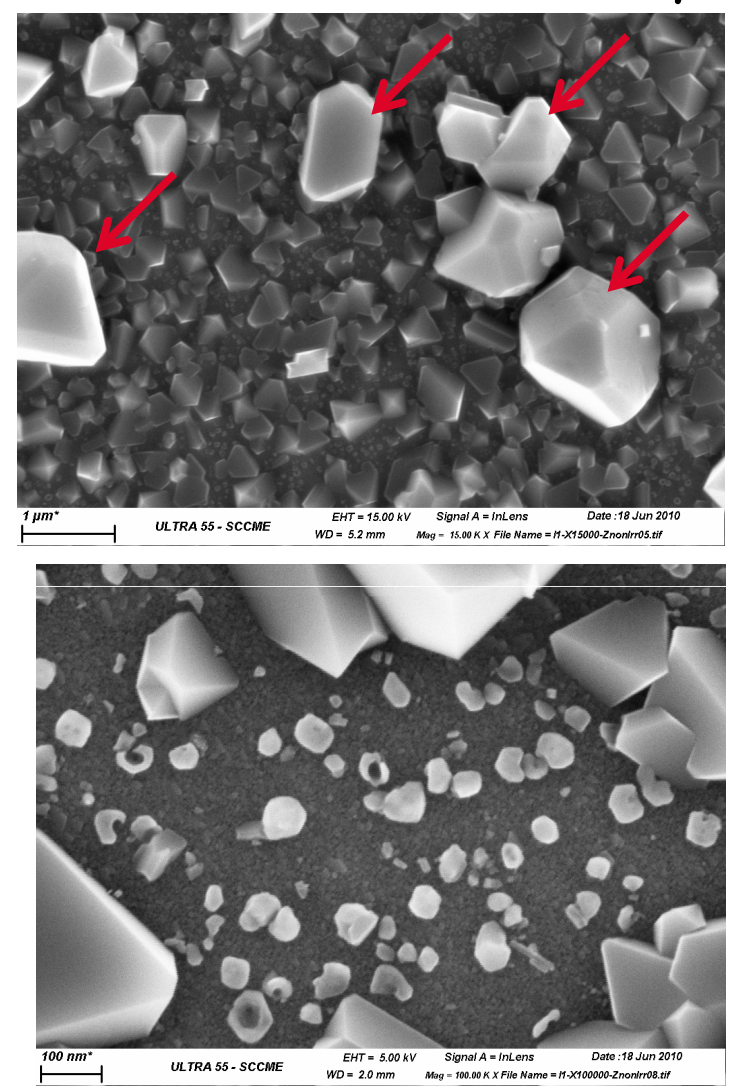

$\times 15000$

$\times 100000$
Irradiated alloy
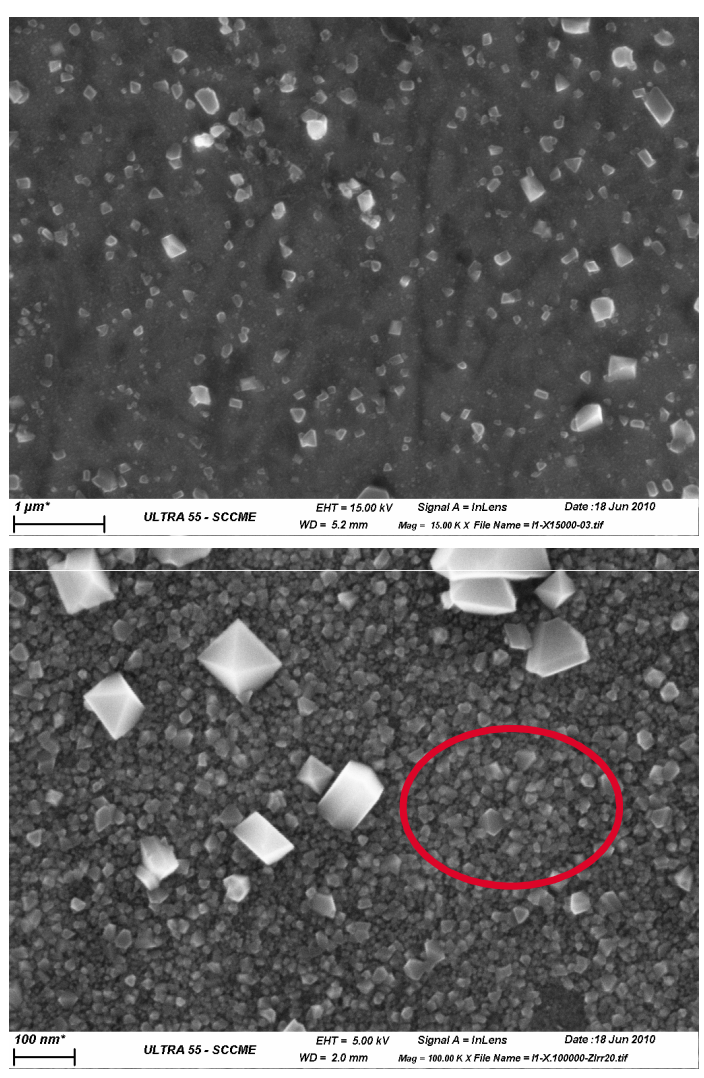

$\Rightarrow$ Bigger cristallites (external layer) on non irradiated sample $\Rightarrow$ Lot of very small cristallites (external layer) on irradiated sample $\underset{\text { CEA - DEN }}{\rightarrow} \frac{\text { influence of irradiation on nucleation/growth of external layer }}{\text { MINOS Workshop - December 5-7, 2012, CEA - INSTN Saclay, France }}$ 


\section{cea}

\section{Effect of irradiation on the internal layer (after $2^{\text {nd }}$ sequence)}

MINDS Short second sequence (no significant oxyde layer growth) -> determination of diffusion coefficient: Dgb

SIMS analysis (collaboration F. Jomard (CNRS))

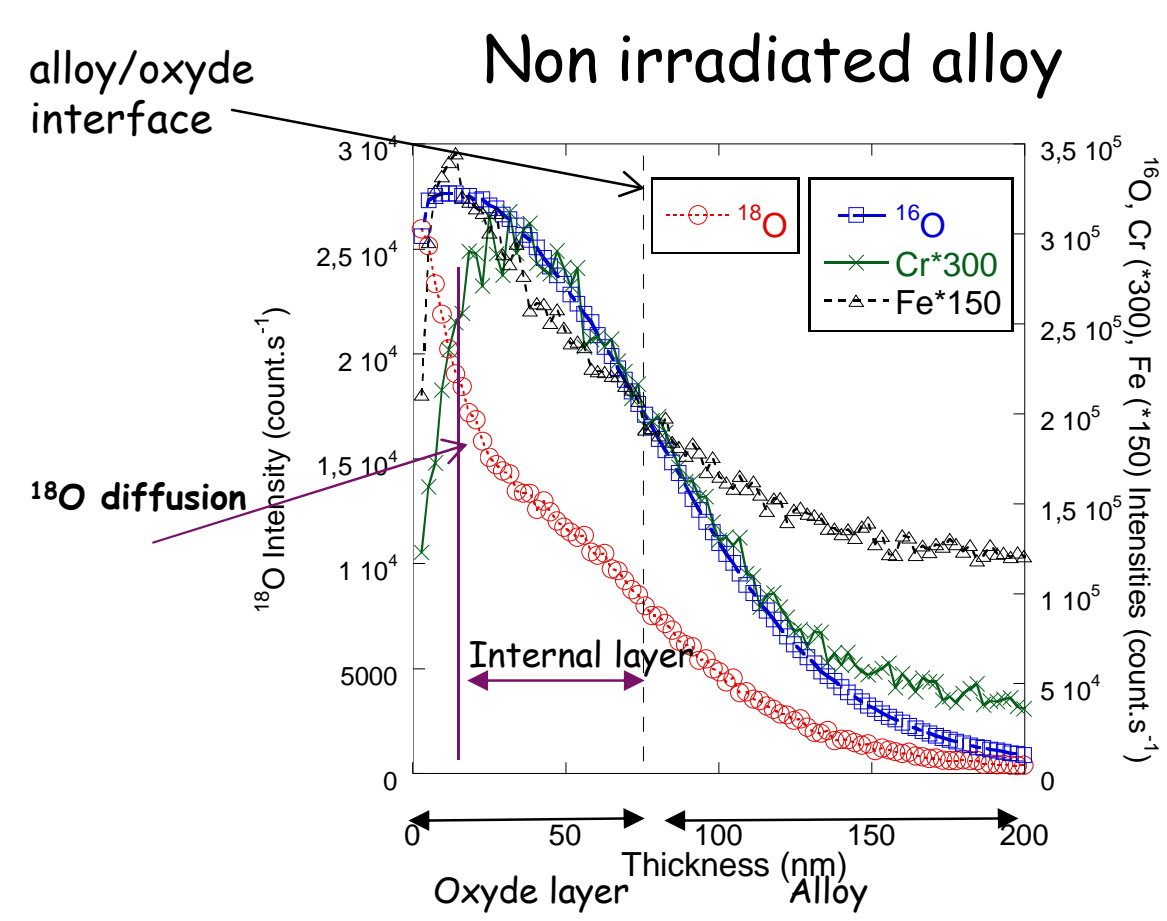

Diffusion at oxyde gbs

${ }^{18} \mathrm{O}$ diffusion profile

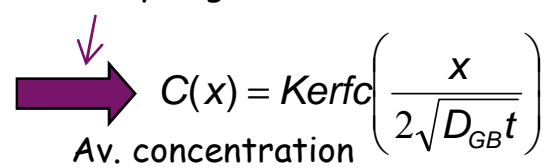

alloy/oxyde

Irradiated alloy

interface $3+0^{4}$

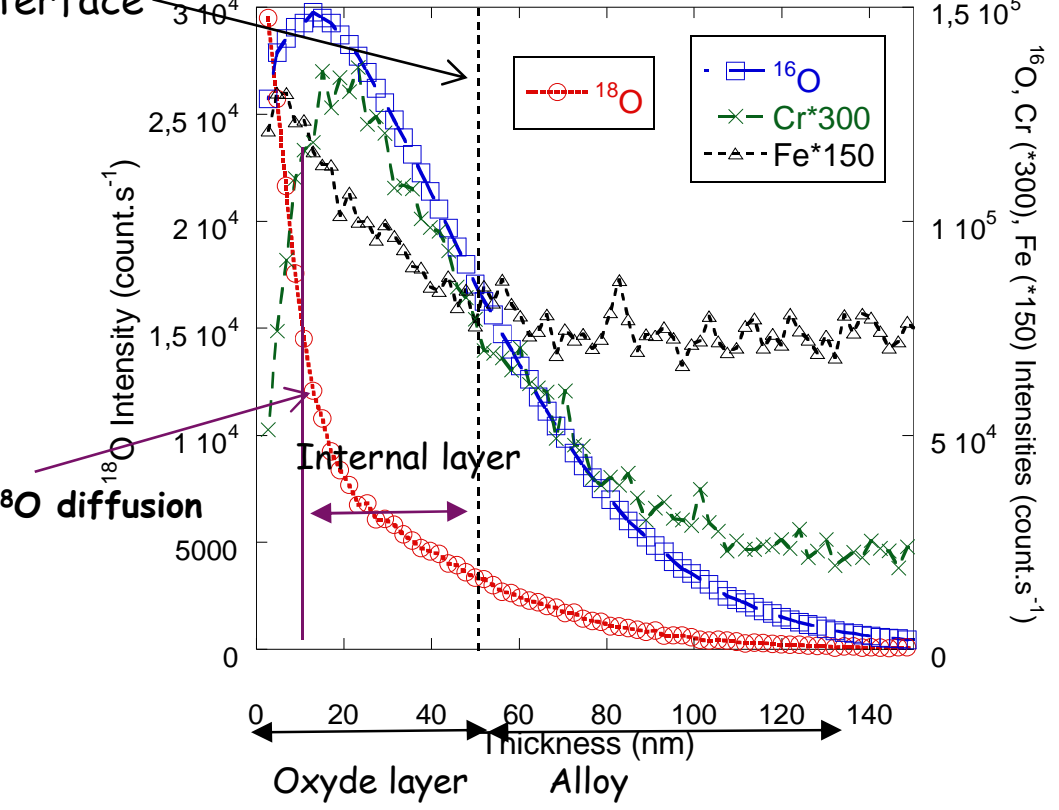

$\rightarrow$ diffusion is faster for non irradiated samples.

\begin{tabular}{|c|c|c|}
\hline & $\begin{array}{c}\text { Non } \\
\text { irradiated }\end{array}$ & Irradiated \\
\hline $\operatorname{Dgb}\left(\mathrm{cm}^{2} \cdot \mathrm{s}^{-1}\right)$ & $\sim 3.10^{-16}$ & $\sim 5.10^{-17}$ \\
\hline
\end{tabular}




\section{cea}

\section{Effect of irradiation on the internal layer (after $2^{\text {nd }}$ sequence)}

\section{MINDS}

Long second sequence (growth of oxyde layer) -> determination of corrosion mechanisms

\section{SIMS analysis (collaboration F. Jomard (CNRS))}
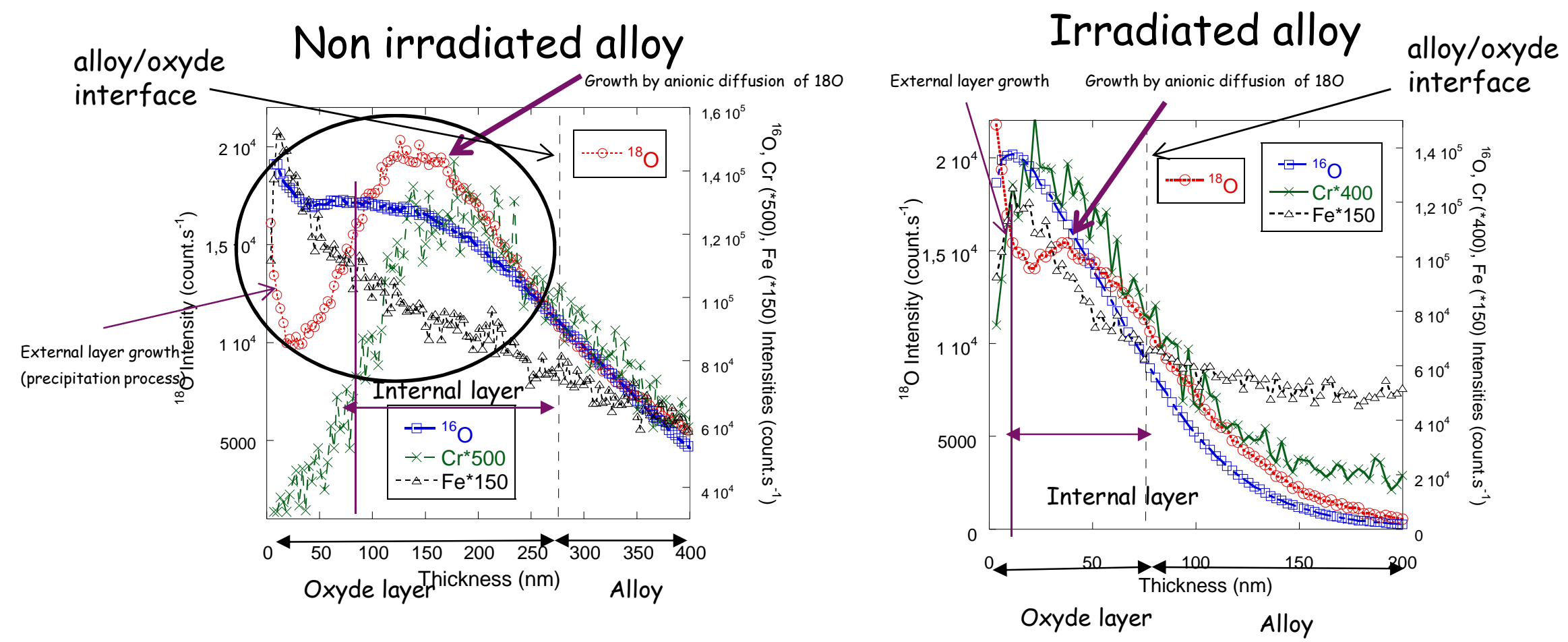

$\Rightarrow$ confirms that this diffusion is faster for non irradiated samples.

$\Rightarrow$ Accumulation of ${ }^{18} \mathrm{O}$ close to the alloy-oxyde interface: anionic diffusion along the grain boundaries of the oxide as the mechanism of internal layer growth 


\section{EFFECT OF LOCALIZATION ON GRAIN BOUNDARY MICROCRACKS NUCLEATION (DYNAMIC STRAINING)}




\section{Methodology: cristalline constitutive laws + FE simulations}

\section{- MINDS}

SEM observations: microcrack nucleation observed at the intersections of channels \& grain boundaries

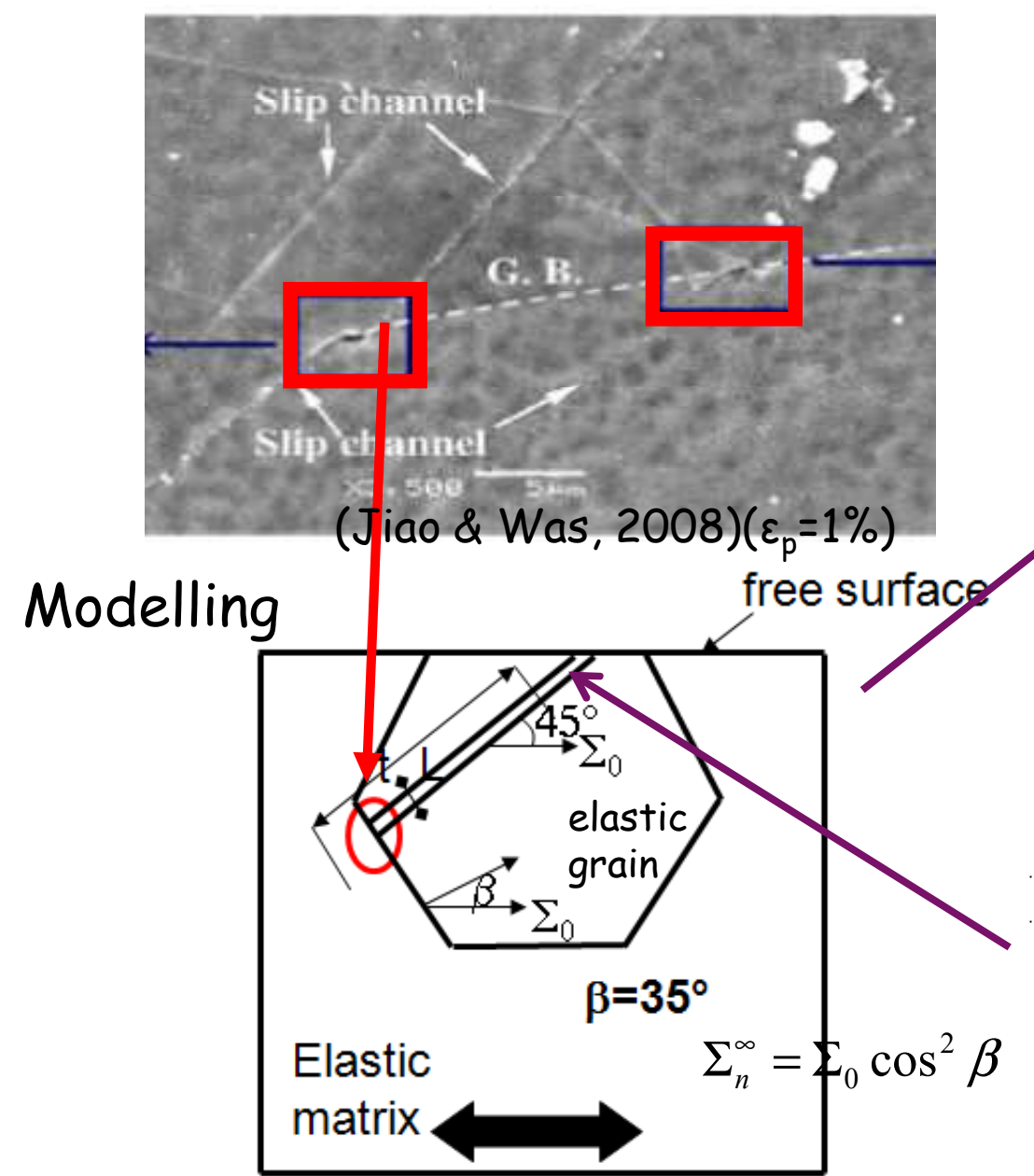

Tensile axis $\Sigma_{0}$
Grain boundary stress fields induced by the impingement of pre-existing channels

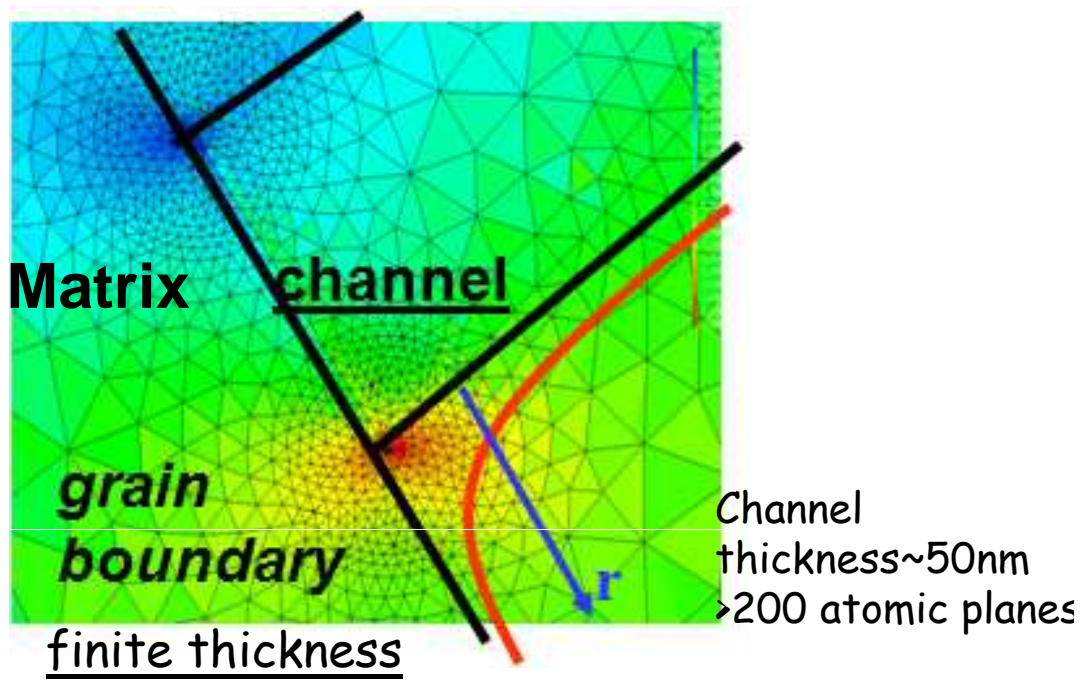

Mechanical behavior of

the clear band

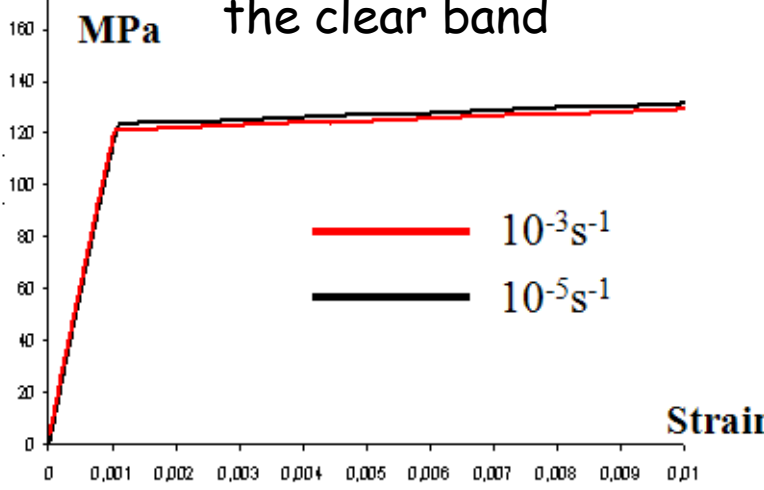

Time-independent behavior Quasi perfect plasticity $\rightarrow$ Critical shear stress: $T_{0}$ $\rightarrow$ Hardening slope: $H$ $\rightarrow$ Latent hardening parameter: $q$ 


\section{cea}

\section{Comparison with the predictions of the pile-up theory: 'close-field' -'far-field'}

\section{\%MIN口S}

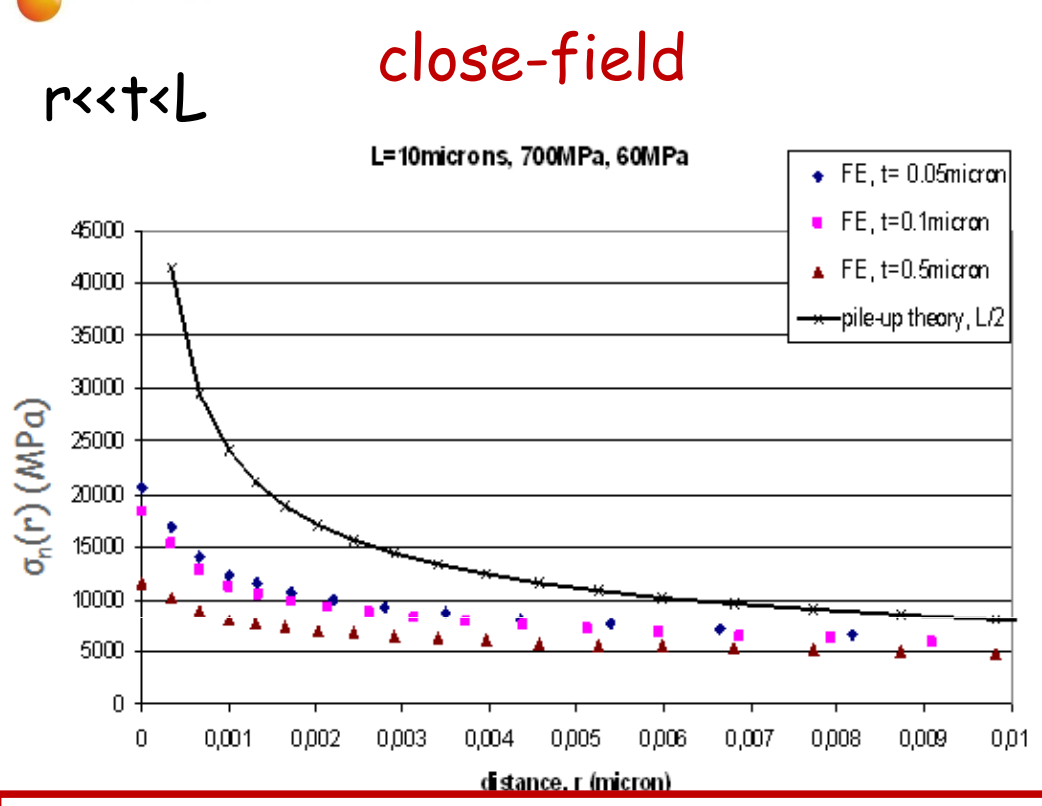

$\rightarrow>$ Large overestimation by the pile-up theory (stress exponent: 0.5) using a length equal to onehalf of the grain size

$\rightarrow$ Very close to the intersection of the channel and grain boundary: weaker singularity due to - the notch effect $\rightarrow \sigma_{n}(r) \sim 1 / r^{a}, a=0.32<0.5$ $(t<r)$

-slip band plasticity

-single slip

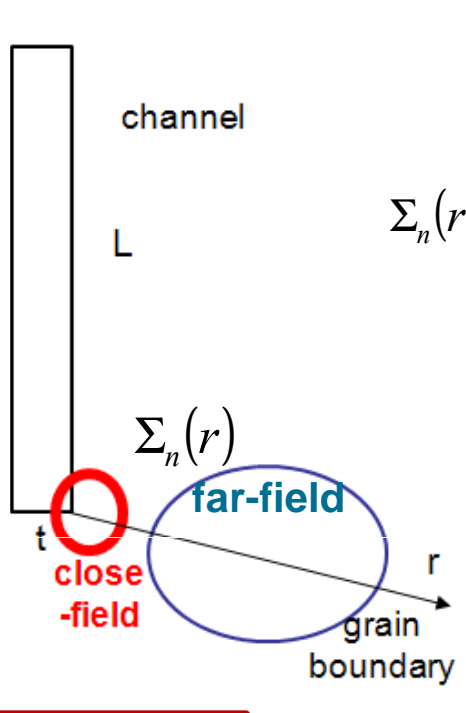

$\underline{t<r<L}$

far-field

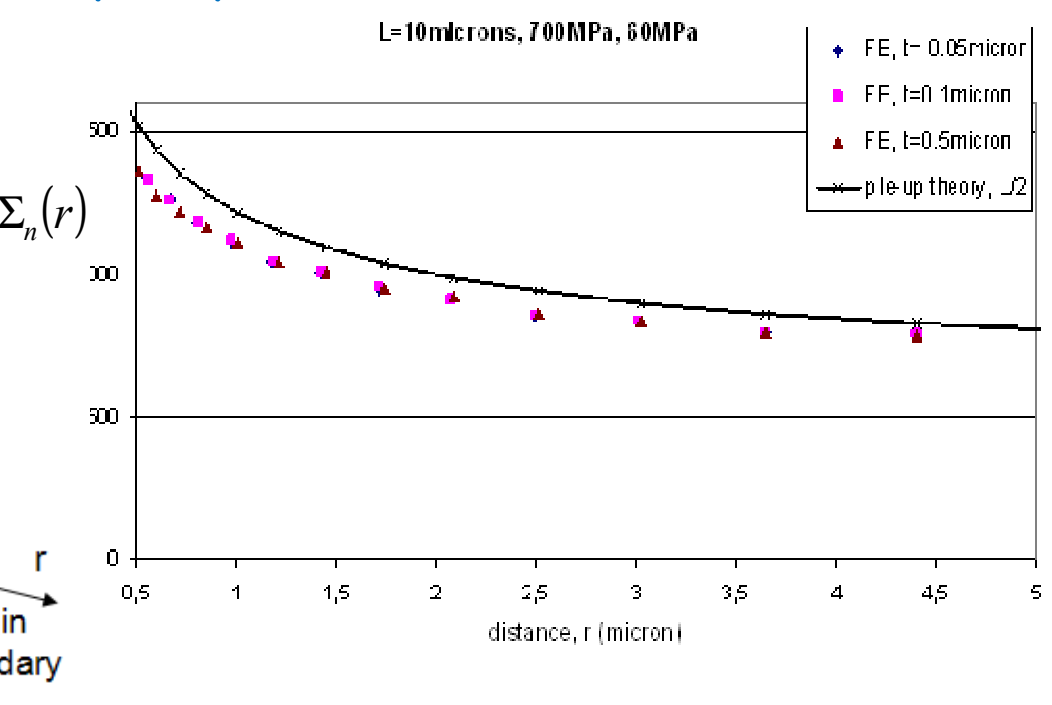

- Whatever the grain size $L$ and the aspect ratio, $L / t$, the discrepancy between the pile-up theory prediction and the curves computed by the FE method is lower $10 \%$ -In fact, if $r>t$, the stress singularity is very close to the pile-up or crack one as expected (Leguillon et al., 2007) 


\section{Effect of localization on grain boundary crack nucleation}

MINDS Prediction of remote stress to GB microcrack nucleation based on:

- An energy balance criterion (fracture energy: $\gamma_{\text {fracture }}$ )

- A critical stress criterion using:

$\Sigma_{c}=(1 / f)\left(\tau_{0}+\left(\frac{2 \lambda}{Y C}\right)^{1-\lambda} A^{1-2 \lambda}\left(\frac{t}{L}\right)^{1 / 2}\left(\frac{d_{0}}{t}\right)^{1-\lambda} \sqrt{\frac{Y \gamma_{\text {fract }}}{d_{0}}}\right)$

$$
\sigma_{c}=\sqrt{\frac{Y \gamma_{\text {fract }}}{d_{0}}}
$$

channel lengths, $t, L$ [microstructure, (dose)]

the Schmid factor, $f$, channel critical shear stress, $\tau_{0}$ [dose] fracture energy, $\left(2 \gamma_{s}-\gamma_{G B}\right)$ [oxydation, dose]

without oxidation: (Sauzay \& Vor, Eng. Fract. Mech., in press)

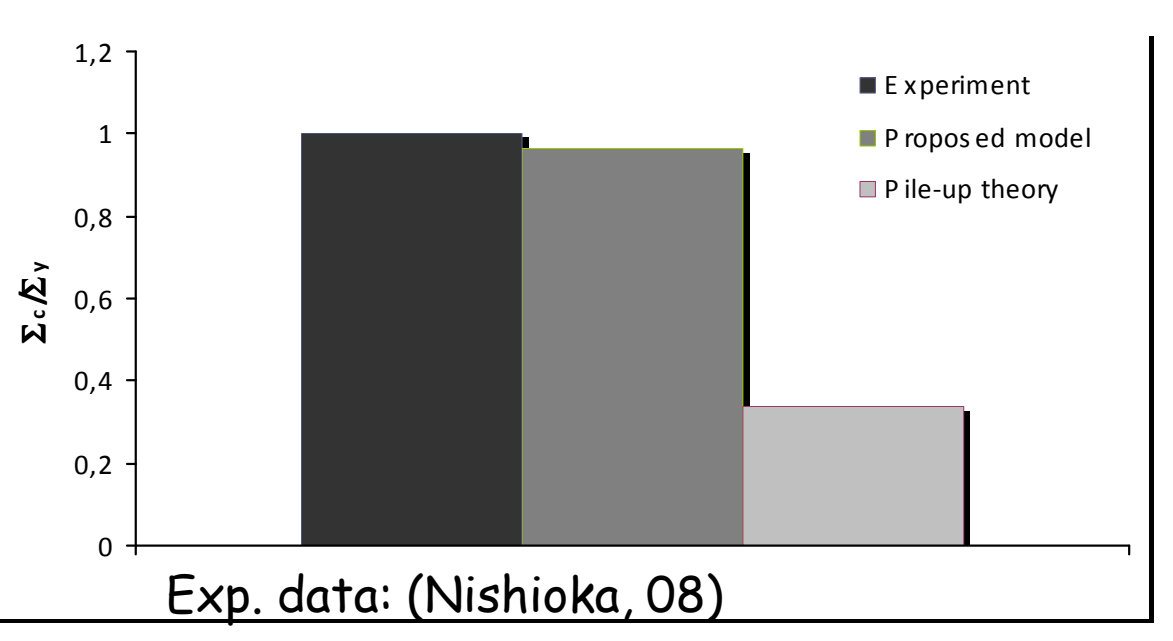

PWR water tensile tests, $320^{\circ} \mathrm{C}$

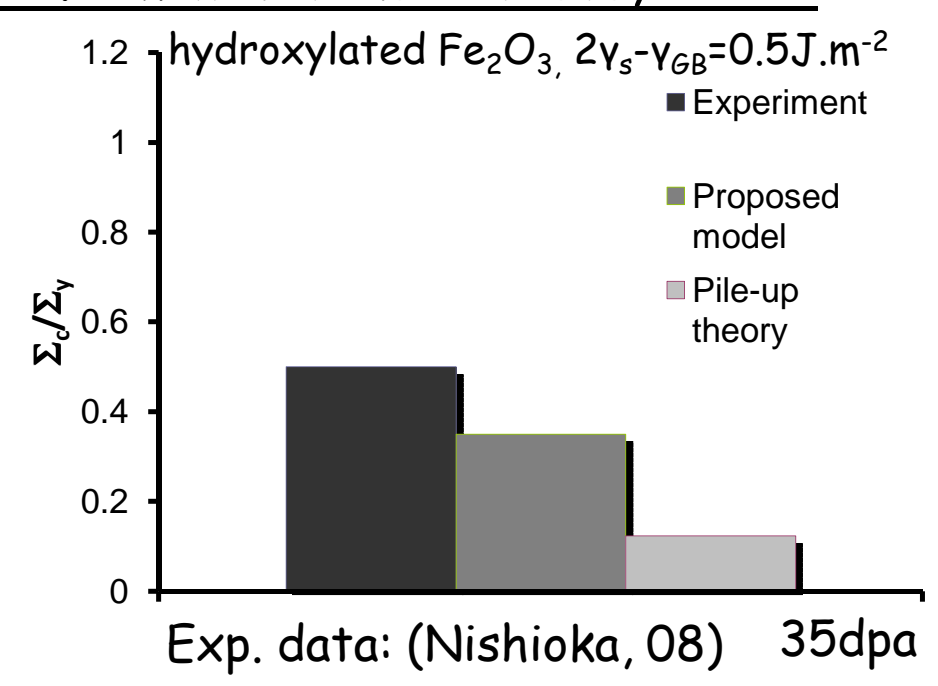

$\left.\mathrm{J} / \mathrm{m}^{2}\right) \rightarrow \mathrm{n} \rightarrow$ Developped criteria leads to an improvment of experiments description

CEA - DEN B. Tanguy 


\section{INVESTIGATION OF CLEAR BANDS FORMATION MECHANISMS}




\section{Methodology: 3D-DD simulations}

\section{MIN口S}

Type 1: boundary conditions simulation volume $\rightarrow$ investigation of single clear band formation mechanisms

- Random prismatic loop positions ( $D=10 \mathrm{~nm}, \mathrm{~L}$ $=50 \mathrm{~nm}), 3.7^{\star} 10^{22}$ loops $/ \mathrm{m}^{3}(<1 \mathrm{dpa})$ - Loops resistance is intrinsic for srew dislocation

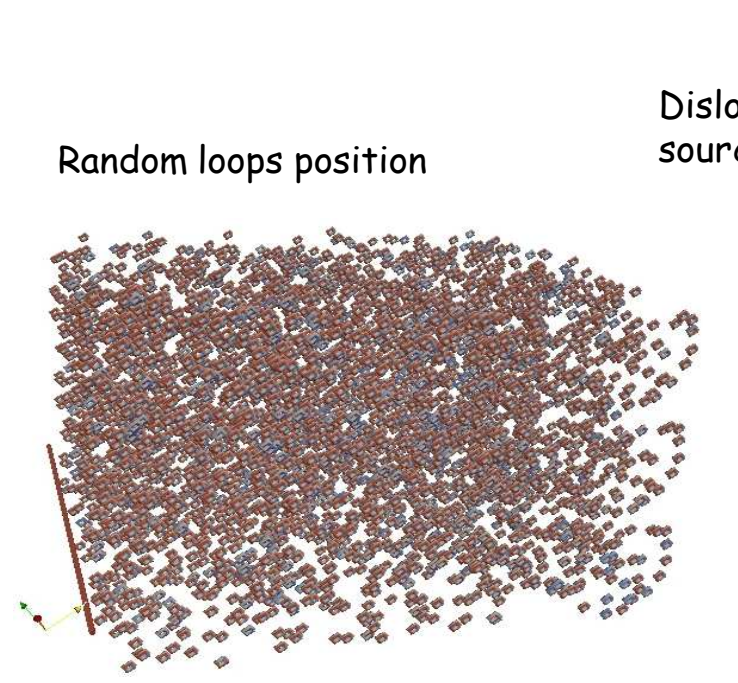

Thermally activated cross-

slip is switch off

$$
\text { CEA - DEN B. Tanguy }
$$

Type 2: boundary conditions simulation volume $\rightarrow$ investigation of clear band multiplication - Random positions, loops=planar internal obstacles (facets, $D=10 \mathrm{~nm}), 1 \star 10^{22}$ loops $/ \mathrm{m}^{3}(<1 \mathrm{dpa}), \varepsilon_{\mathrm{p}}=1.4^{\star} 10-3$ - Facets resistance $=f$ (incoming dislocation type)

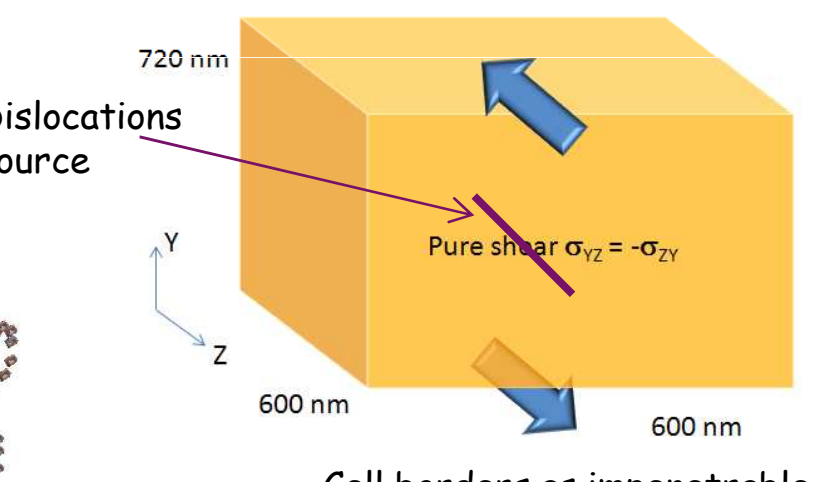

Cell borders as impenetrable grain boundaries
Single loop $=1$ soft Facet

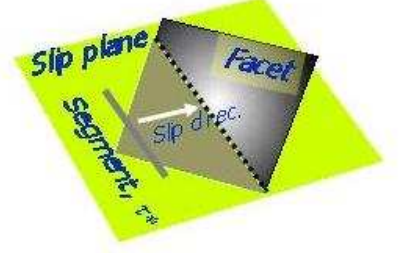




\section{cea}

\section{Dislocation-loop interactions based on MD simulations (type 1)}

MINDS Goal: introduction of loop-induced evolutions in DD simulations
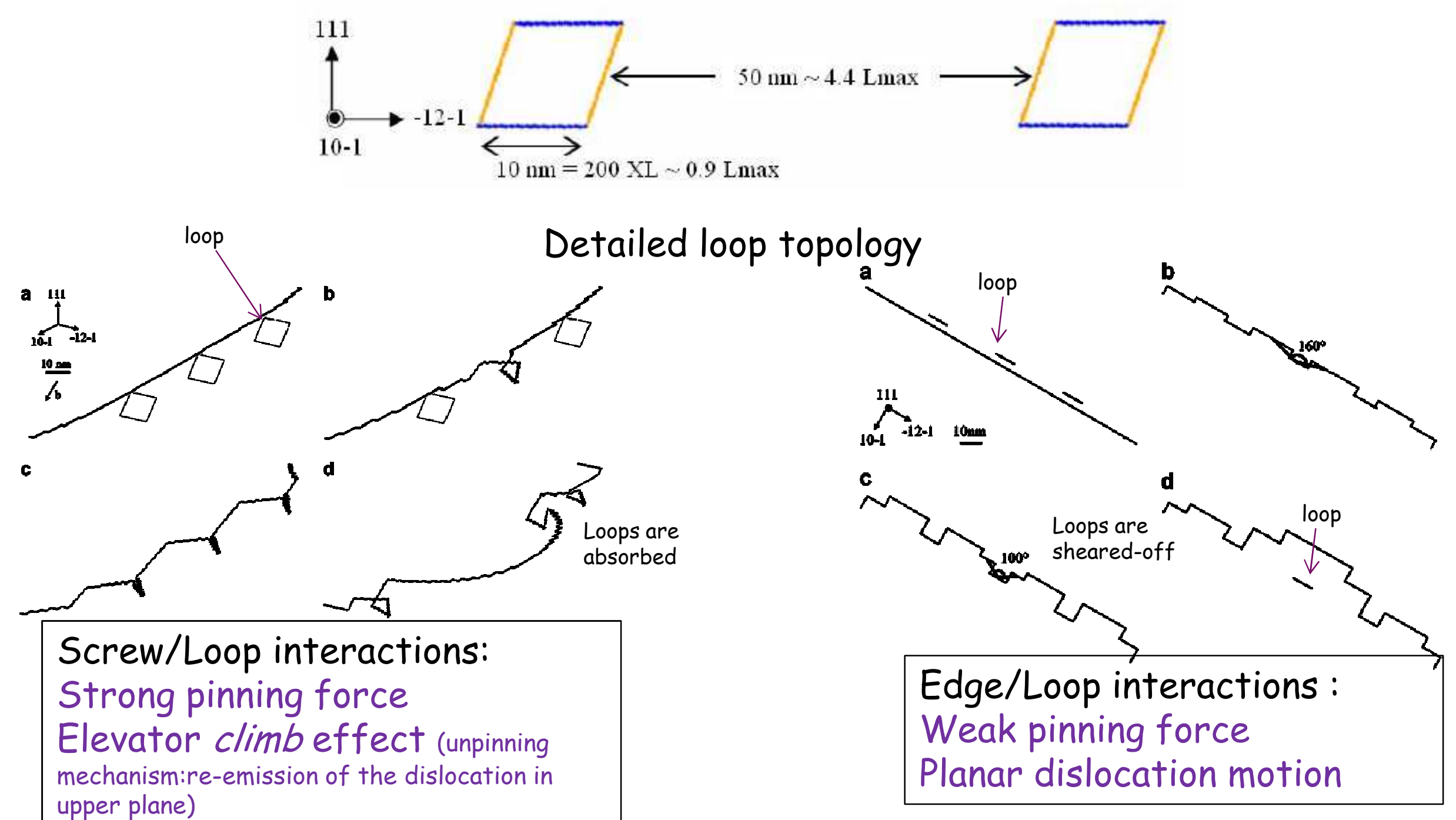
upper plane) 


\section{cea}

\section{Details of single clear band formation (type 1 simulations)}

MIN口S

View of simulation cell after the clear band formation

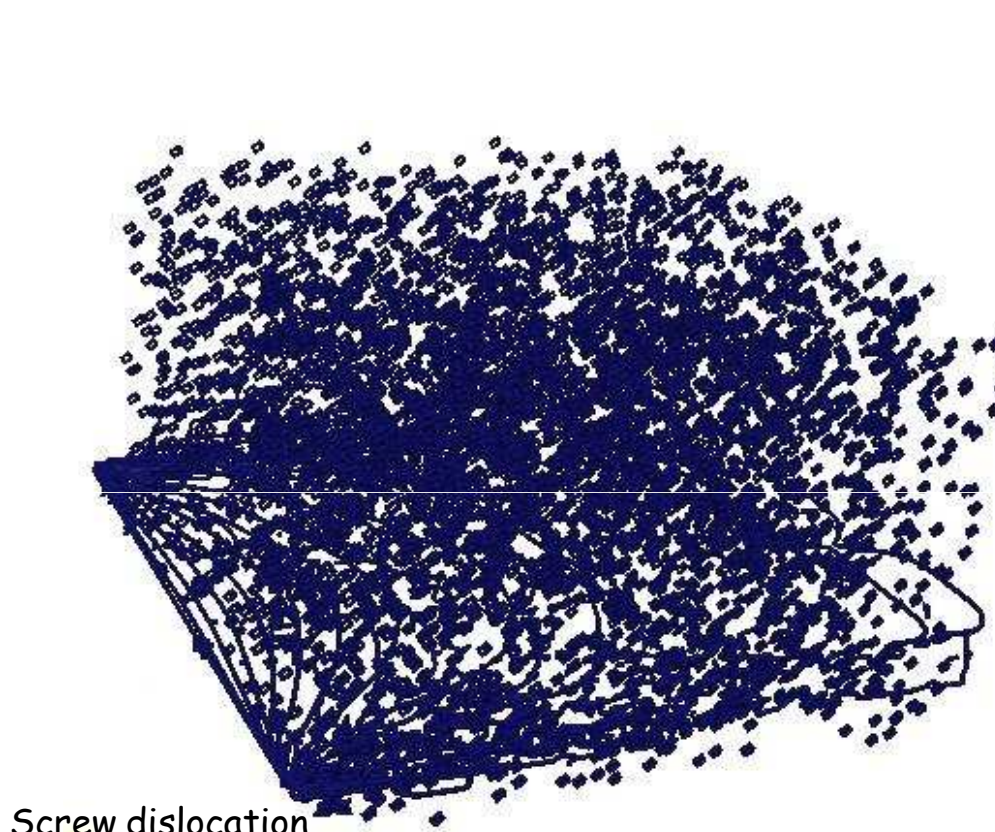

$\rightarrow$ Dislocation glide only possible through a collective mechanism: leading dislocations clear the band. Trailing dislocations concentrate the stress on leading dislocations by piling-up

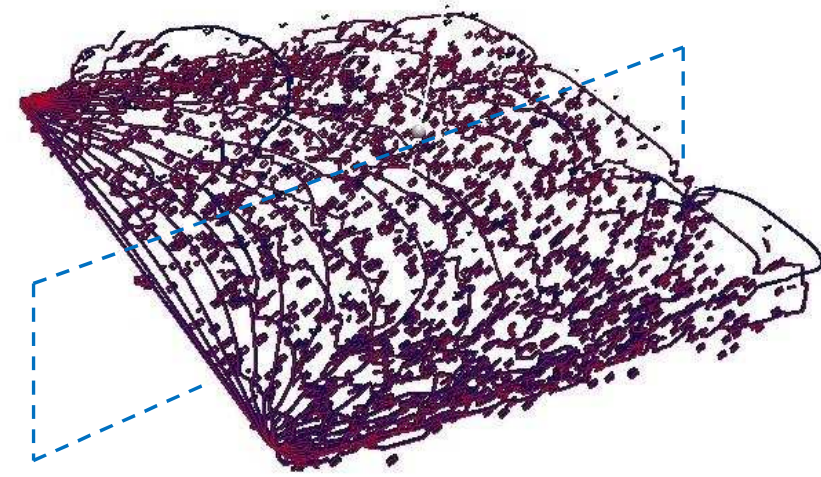
effect
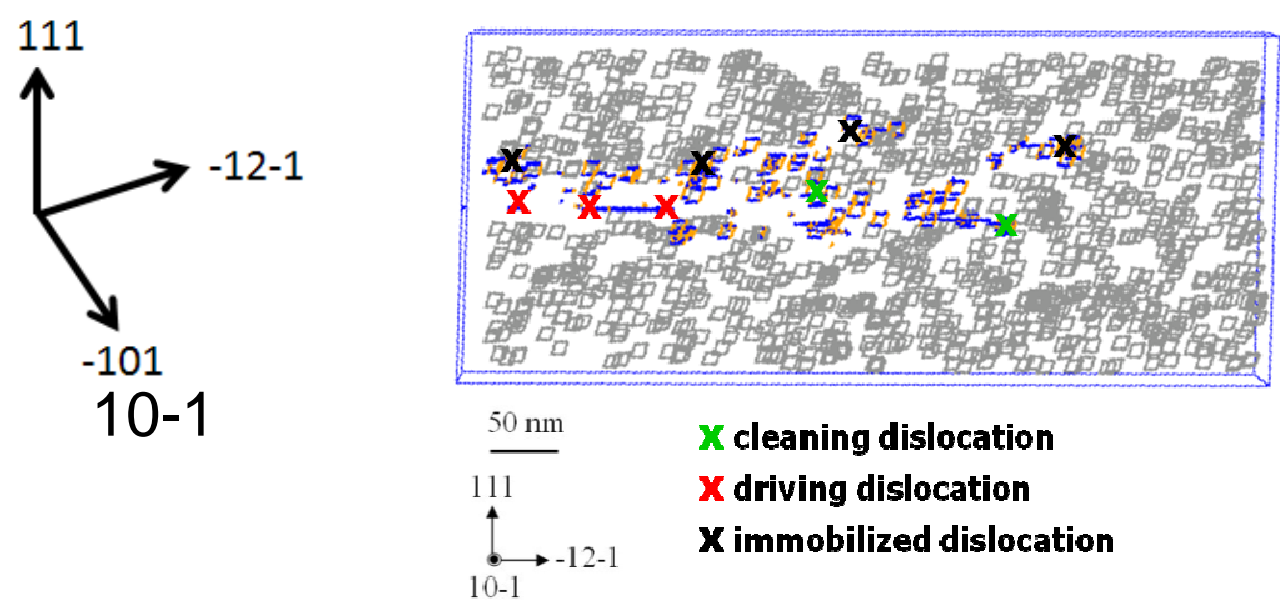

-> clear band with finite thickness is due to collective dislocation effects: pile-up formation and arm exchange 


\section{cea}

\section{Investigation of clear band multiplication (type 2 simulations)}

\section{$\because$ MINDS}

Acute cross-slip (long range mechanism): clear band multiplication mechanism

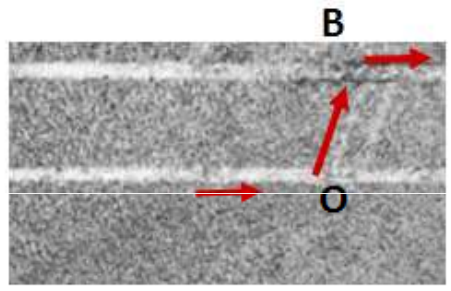

$$
\text { No loops } \varepsilon_{n}=1,4 \times 10^{-3} \varepsilon_{p}^{10^{22} \text { loops } / \mathrm{m}^{3}(\sim 0.5 \mathrm{dpa})} \varepsilon_{\mathrm{p}}=1,4 \times 10^{-3}
$$

DD simulation

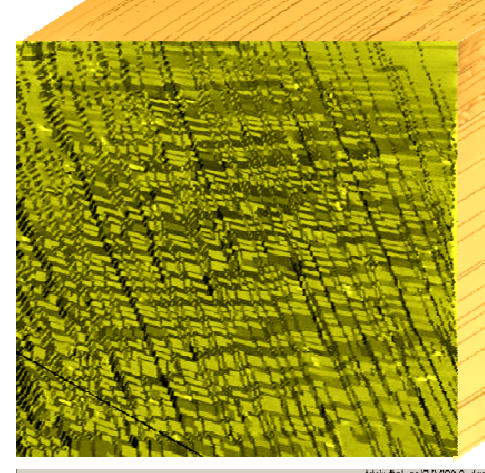

Observation: AFM

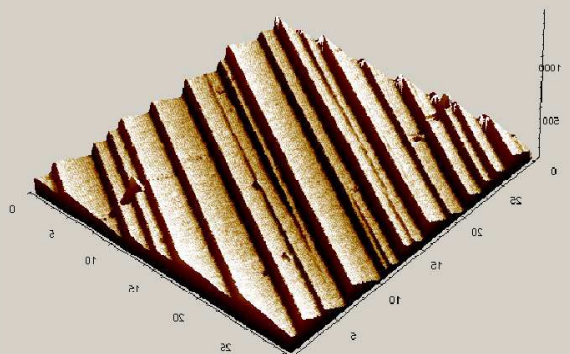

Surface deformation before ion irradiation

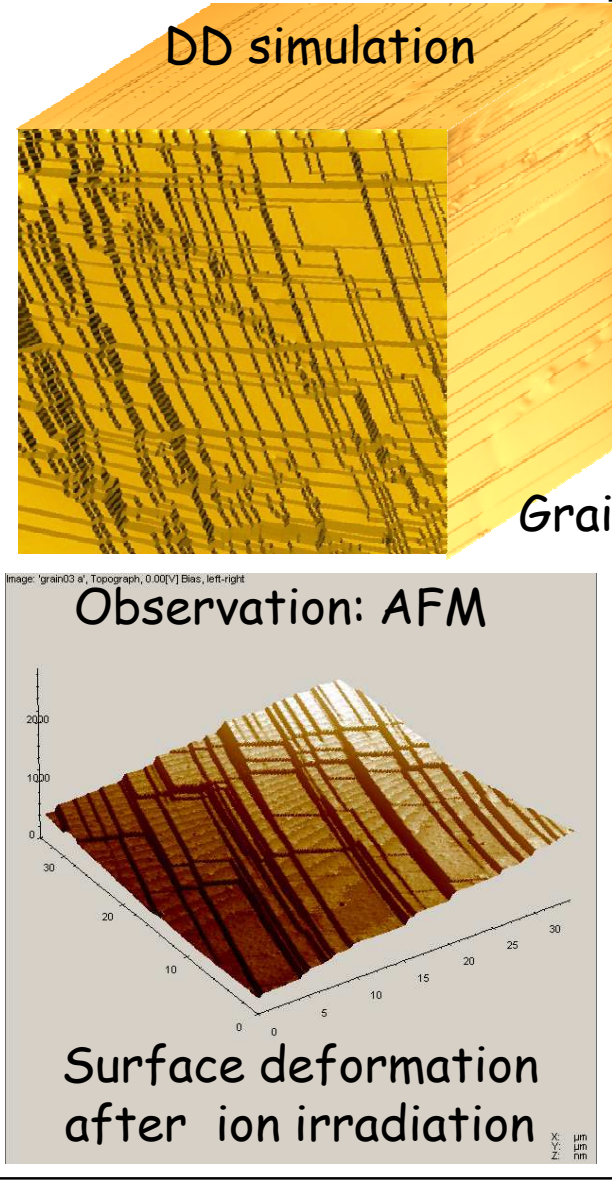

The number of slip bands per unit volume: trends are correctly described $\rightarrow$ radiation-induced strain localization is well captured by DD model 


\section{Micro-mechanical model predictions (type 2 simulations)}

MINDS

-> 3 influential parameters: grain size, irradiation hardening and SFE

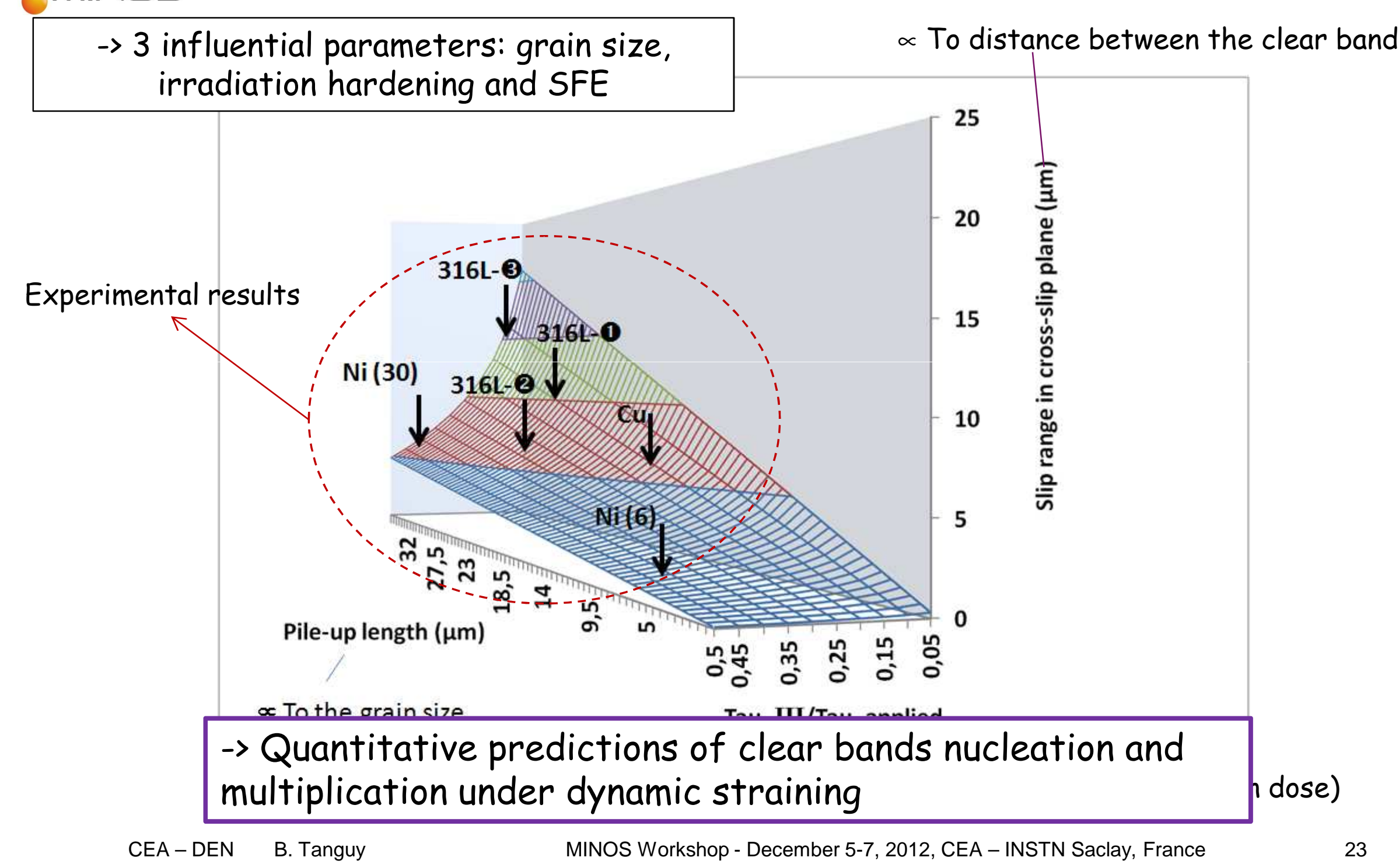

$\propto$ To distance between the clear bands 


\section{Conclusions: Overview of the studies related to Internals at CEA}

MINDS

Microstructure and radiation hardening

Radiation Induced segregation

Localization of the deformation

Swelling

Irradiation Creep

SCC of irradiated material

In-reactor IASCC CEÁA-EEEIN B. B. TanguY
Experimental

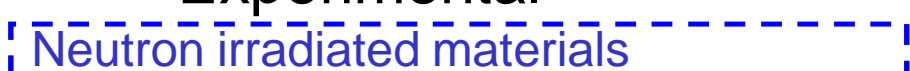

Mechanical tests

TEM

TEM-EDX, TAP

Mechanical tests, TEM

Irradiation at high doses,

Swelling measurement, TEM

In-reactor creep tests,

TEM

SCC tests on

recirculation water

loop

Swelling mandrel

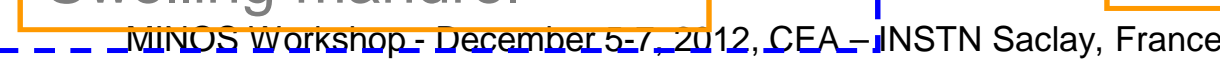

Modelling

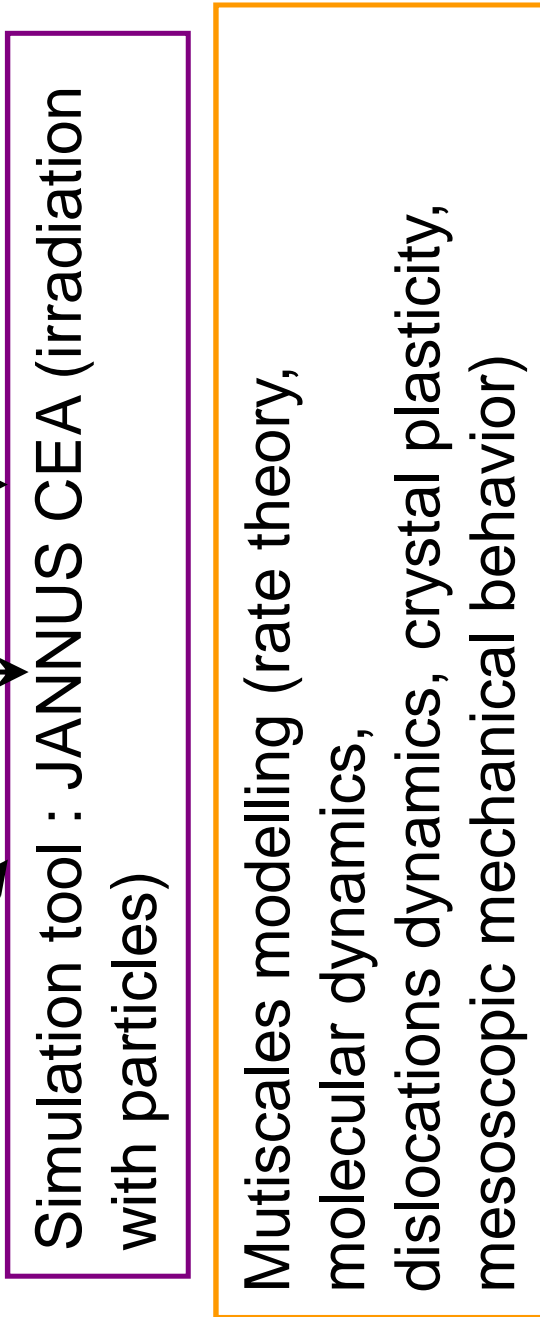

24 


\section{Thank you for your attention}

With contribution of $L$. Marchetti, P. Bossis, P. Billaud, J-P. Gozlan, O. Rabouille, C. Pokor

With financial and technical support of PCRD7 Perform60, CEA RSTB program (projects RACOC and MASOL), EDF R\&D Project Internals 